\title{
Amphibole control on copper systematics in arcs: Insights from the analysis of global datasets
}

\author{
Nicholas D. Barber ${ }^{\mathrm{a}, *}$, Marie Edmonds ${ }^{\mathrm{a}}$, Frances Jenner ${ }^{\mathrm{b}}$, Andreas Audétat ${ }^{\mathrm{c}}$, \\ Helen Williams ${ }^{\text {a }}$ \\ ${ }^{a}$ Department of Earth Sciences, University of Cambridge, United Kingdom \\ ${ }^{\mathrm{b}}$ School of Environment, Earth, and Ecosystem Sciences, The Open University, United Kingdom \\ ${ }^{\mathrm{c}}$ Bayerisches Geoinstitut, Universität Bayreuth, Germany
}

Received 8 January 2021; accepted in revised form 17 May 2021; Available online 23 May 2021

\begin{abstract}
Copper, obtained from porphyry deposits formed in arc settings, is a critical resource, and is primarily sourced from magmas. However, the processes that shape the copper contents of arc magmas are up for debate. Existing models place emphasis on different petrological agents that explain large-scale trends in copper systematics. Previous studies have noted the ' $\mathrm{Cu}$ paradox,' where the magmas with high $\mathrm{Sr} / \mathrm{Y}$ ratios, indicative of ore-forming potential, have the lowest copper concentrations. Here we compile a multidimensional database of volcanic whole rock compositions and couple it with simple petrological models to elucidate the controls on volcanic whole rock compositions with respect to $\mathrm{Cu}$. We show that calc-alkaline, high $\mathrm{Sr} / \mathrm{Y}$ magmas undergo major element modification caused by extensive amphibole and/or garnet fractionation, which promotes sulphide precipitation and copper depletion. We demonstrate the importance of amphibole fractionation as a globally important process that promotes both calc-alkaline differentiation and sulphide fractionation in arc magmas, as well as its role in signalling the right set of chemical conditions in magmas that ultimately feed copper porphyry deposits. This work also raises the possibility of amphibole as a geochemical and petrological indicator of potential porphyry-forming conditions in a magma, which we show should be readily detectable by a combination of different geochemical metrics. Despite their paucity in copper, high $\mathrm{Sr} / \mathrm{Y}$ magmas are associated with porphyry deposits, implying that the propensity of magmas to form such deposits depends on factors other than a magma's bulk copper content.

(C) 2021 The Author(s). Published by Elsevier Ltd. This is an open access article under the CC BY license (http://creativecommons.org/ licenses/by/4.0/).

Keywords: Copper systematics; Global datasets; Amphibole; Sulphide stability; GIS; Igneous differentiation; Subduction zones; Porphyry deposits
\end{abstract}

\section{INTRODUCTION}

Copper $(\mathrm{Cu})$ is economically important owing to its role in the development of electrical components and its critical status in the transition to green energy (Arndt et al., 2017). Porphyry deposits, which are temporally and spatially associated with arc magmatism (Fig. 1), account for over $70 \%$

\footnotetext{
* Corresponding author.

E-mail address: ndb38@cam.ac.uk (N.D. Barber).
}

of global $\mathrm{Cu}$ ore production (Singer et al., 2005), and significant amounts of $\mathrm{Au}$ and Mo production (Singer et al., 2005). Great progress has been made in developing a general model of porphyry development (Richards, 2015; Chiaradia and Caricchi, 2017; Blundy et al., 2015; Wilkinson, 2013; Lee and Tang, 2020; Richards, 2003; Richards, 2011), yet more work needs to be done to understand how these processes are expressed in modern volcanic environments (Hedenquist et al., 1994). Prevailing magmatic models of $\mathrm{Cu}$ porphyry formation focus on two 


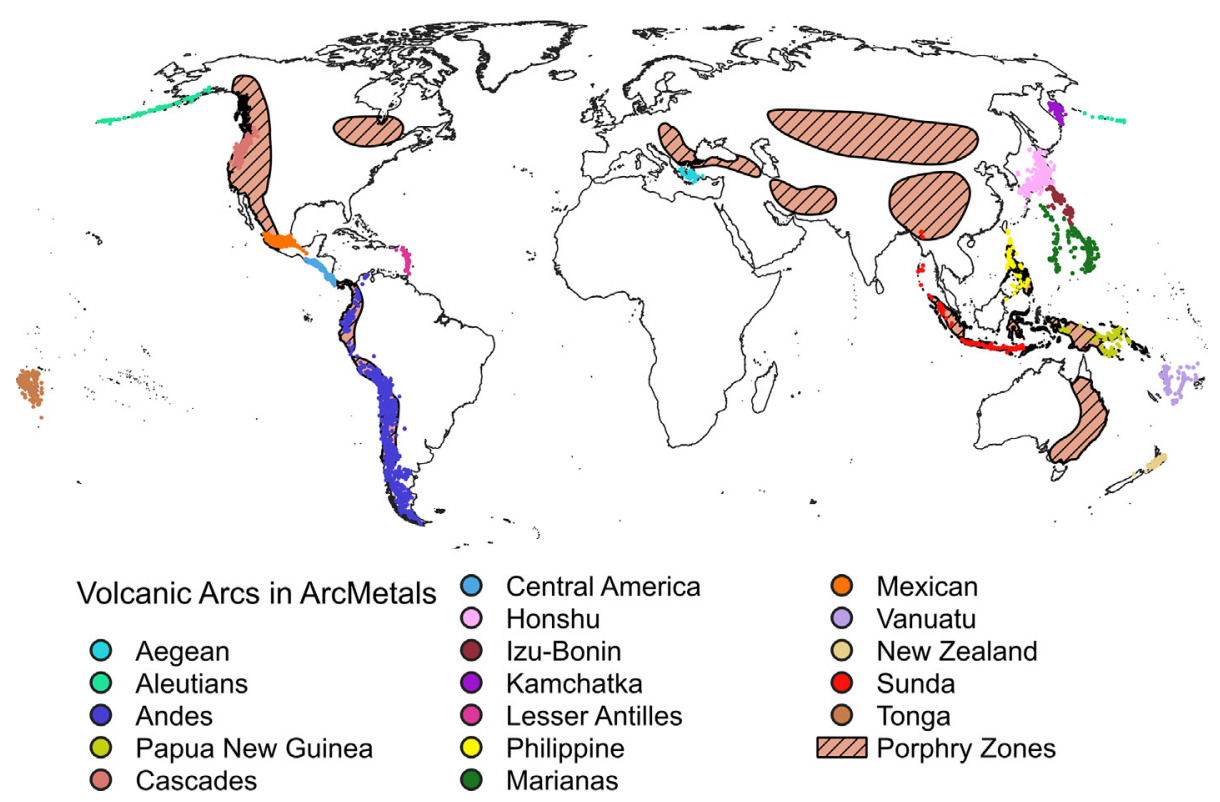

Fig. 1. Global distribution of samples used in ArcMelts, our global data compilation. Sample locations are color coded by arc. Samples are overlayed on zones of porphyry mineralization, taken from Singer et al. (2005). Created using QGIS 3.10. (For interpretation of the references to colour in this figure legend, the reader is referred to the web version of this article.)

important processes, which may promote $\mathrm{Cu}$ enrichment, transport, and deposition in and around porphyry stocks: (i) the saturation of the magma in sulphide (an Fe and $\mathrm{S}$ bearing liquid or mineral phase), into which $\mathrm{Cu}$ partitions strongly (Kiseeva and Wood, 2013; Kiseeva et al., 2017; Patten et al., 2013; Jugo et al., 1999; Simon et al., 2006; Li and Audetat, 2015; Li and Audetat, 2013), a process which may deplete the magma $\mathrm{Cu}$ when sulphide fractionates, but may also enrich a magma if sulphide is remobilised by hotter or more oxidised magma (Wilkinson, 2013; Park et al., 2019; Jenner et al., 2010; Chiaradia, 2014); and (ii) the exsolution of a volatile phase, which may unmix to a brine and vapor at low pressure (Hedenquist et al., 1994), into which $\mathrm{Cu}$ and other metals partition and eventually precipitate from, leading to ore deposition (Edmonds and Mather, 2017; Blundy et al., 2015; Nadeau et al., 2010; Audetat et al., 2008).

A number of models have been proposed to explain how these processes may enhance a magma's potential to eventually go on and form a mineralized deposit. Recently, it has been suggested that sulphide saturation may be avoided by simultaneous Fe depletion and auto-oxidation caused by garnet fractionation (Lee and Tang, 2020). Garnet's preference for $\mathrm{Fe}^{2+}$ leaves residual magmas enriched in $\mathrm{Fe}^{3+}$ (Lee and Tang, 2020). This in turn produces a more oxidized and evolved melt (with higher $\mathrm{S}^{6}+/ \mathrm{S}^{2-}$ ), which pushes the magma further away from sulphide saturation (Jugo et al., 2010) and may even trigger the dissolution of existing sulphides. It was proposed that this garnet-mediated process could enrich the melt in $\mathrm{Cu}$, which could then be transferred to fluids when porphyry formation commences (Lee and Tang, 2020). Alternatively, others have argued that sulphide accumulation may be critical to later ore development by pre-concentrating a reservoir of localized sulphides at the base of a magma reservoir (Wilkinson,
2013), which is later remobilised by intruding hotter or more oxidised magmas, thereby enriching these magmas in $\mathrm{Cu}$ (Wilkinson, 2013).

However, other studies have de-emphasized the importance of magmatic $\mathrm{Cu}$ contents as an indicator of ore potential (Richards, 2015; Du and Audetat, 2020), promoting instead the importance of magmatic water content (Richards, 2011; Loucks, 2014; Rezeau and Jagoutz, 2020), time scales of magma differentiation (Chelle-Michou et al., 2017), and larger magma volumes (Steinberger et al., 2013) as some of the critical controls on the capacity of a magma to produce a porphyry. Nonetheless, nearly all models agree that the process of sulphide saturation is important for understanding eventual ore formation. Sulphide saturation is a complex process mediated by temperature, pressure, and silicate melt composition, and thanks to continued empirical work the factors leading to sulphide saturation in silicate melts are increasingly well understood (O'Neill, 2020; Smythe et al., 2017; Jugo et al., 2010; Kiseeva and Wood, 2015; Zajacz and Tsay, 2019; Nash et al., 2019). However, it is presently unclear (i) what petrological processes in arc magmas will promote, delay, or are simply associated with sulphide fractionation, and (ii) whether the early fractionation of a sulphide, and associated loss of $\mathrm{Cu}$, is detrimental to later porphyry formation (Park et al., 2019).

One reason that these outstanding questions remain is the measure of sample bias in our existing understanding of $\mathrm{Cu}$ systematics. Crucially, we need to establish what generic petrological processes, if any, can explain the abundances of $\mathrm{Cu}$ in arc magmas in all major subduction zones as a function of sulphide stability. In order to address this need, we compiled a large global database of volcanic arc whole rock compositions (Fig. 1). The ArcMetals database $(\mathrm{N}=55,795)$ contains data from 17 arcs, encompassing geochemical and contextual information such as major, 
trace element and radiogenic isotope compositions, geology, location, and geologic age (see Methods), expanding on the approach taken by earlier studies (Richards, 2015; Chiaradia, 2014; Chiaradia, 2015; Farner and Lee, 2017; Lee and Tang, 2020; Rezeau and Jagoutz, 2020). Combined, these parameters allow us to explore $\mathrm{Cu}$ systematics in all arc settings. We interpret the generic features of ArcMetals with respect to $\mathrm{Cu}$ systematics using models of silicate melt differentiation (Ulmer et al., 2018) and sulphide saturation (O'Neill, 2020) based on recent high-quality experimental studies. This work pushes forward our understanding of key magmatic processes occurring in arcs that influence the capacity of magmas to develop ore deposits. Furthermore, this work provides a framework for further interrogation of major mineral controls on chalcophile metal behaviour in specific volcanic arcs.

\section{METHODS}

\subsection{ArcMetals: data sources and compilation}

\subsubsection{Database design}

This paper presents a new compilation of existing arc volcanic whole rock chemistry called ArcMetals (https:// github.com/ndb38/arc-metals). This database was compiled with several crucial design distinctions in mind which distinguishes it from previous databases. First, we wanted the database to be fully integrated with the spatial dimension of the data. Hence, much of the compilation work takes place in a Geographic Information System (GIS) environment, where we can control and append geophysical and tectonic datasets. As discussed in greater detail both below and in the Supplement, this approach afford us several advantages over prior compilations. Here we take advantage of recent advances in the application of data science and Geographic Information Systems (GIS) in geochemistry, allowing us to build on prior studies that were based on simpler data compilation routines (Lee and Tang, 2020; Farner and Lee, 2017; Chiaradia, 2014; Chiaradia, 2015; Loucks, 2014; Richards, 2015) in the initial compilation and filtration of GeoRoc data, combining existing petrological datasets in ore systematic ways. Subsequently, we apply a range of geospatial techniques to append the maximum amount of geophysical data to this compilation without compromising the extent or quality of this data. This latter step is documented in detail in the Supplement, and is what sets this compilation apart from many previous datasets.

\subsubsection{Geochemistry}

Sample geochemical and analytical data were collected from the GeoRoc (Sarbas and Nohl, 2008) database. These data were compiled using open source python code, available on our GitHub. Initially, 19 arc magma datasets were included in the database, but the Kermadec and Banda files contained so few data upon filtering, that they were ultimately omitted (Fig. 1). Data mainly for arc volcanic rocks were compiled (see Supplement), but a companion plutonic dataset has also been generated (thoguh not discussed in this study). Before filtering, the fully compiled database contained $>200,000$ records. In order to maximize the number of measurements per sample, six filters were applied to the initial compilation: (1) records with data obtained before 1960 C.E. were removed; (2) records with no recorded analytical technique were removed; (3) only those records pertaining to measurements by X-ray fluorescence (XRF), secondary ion mass spectrometry (SIMS), electron microprobe (EPMA), thermal ionization mass spectrometry (TIMS), inductively-coupled plasma mass spectrometry (ICP MS), laser ablation inductively-coupled plasma mass spectrometry (LA ICP MS), and Fourier-transform infrared (FTIR) spectroscopy were retained; (4) the database was reduced to individual records where sample name, material type (whole rock, glass, or inclusion), and analytical technique were the same (e.g. if 1 whole rock sample had 4 records in GeoRoc measured using XRF, this filter would reduce the 4 records to one average for XRF); (5) records with the same sample name and material type were averaged and collapsed into one record. This had the effect of, for example, combining a sample's ICP MS measured trace elements with its XRF derived major elements; (6) samples that had the same element measured more than once using the same technique were removed. This filter only affected a small subset (a few hundred) samples, but having it in place makes it easier to quantify analytical errors (see Supplement). Before plotting, the final database was filtered to only include those magmas with a reported loss on ignition (LOI) less than $3.5 \mathrm{wt} . \%$, following approaches used in similar databases (e.g. Loucks, 2014).

\subsubsection{Geophysical parameters}

Several global geophysical datasets were appended to the main database using the geospatial software QGIS 3.14. The data we appended included subducting slab surfaces and geometry generated from extensive seismic records (slab dip, depth to slab, slab thickness) (Hayes et al., 2018), crustal thickness (Szwillus et al., 2019), and subducting plate sediment cover thickness (Pasyanos et al., 2014). Every sample record in the database was linked to the geophysical datasets, which have good global coverage at a resolution of $10-100 \mathrm{~km}^{2}$. A sub-population of database records had additional geophysical data appended based on their proximity to Holocene volcanoes (Syracuse and Abers (2006). These data included convergence rate, slab thermal parameter, and slab age (Syracuse and Abers, 2006). The full QGIS methods and compilation scripts can be found in the Supplement.

\section{RESULTS}

We present summaries of global volcanic whole rock geochemical data in Figs. 2, 3, 4, 5 and 9. These are discussed and interpreted in Section 4, in light of modeling done to validate these trends (Figs. 6-8). Fig. 2a shows volcanic whole rock $\mathrm{Sr} / \mathrm{Y}$ versus $\mathrm{SiO}_{2}$, colour-coded for the different arcs (Fig. 2b), Cu content (Fig. 2c) and crustal thickness (Fig. 2d). It has been shown that magmas fertile for porphyry $\mathrm{Cu}$ deposit formation have high whole rock $\mathrm{Sr} / \mathrm{Y}$ ratios at intermediate to felsic magma compositions (Fig. 2, (Richards, 2011; Loucks, 2014; Chiaradia, 2015)). 

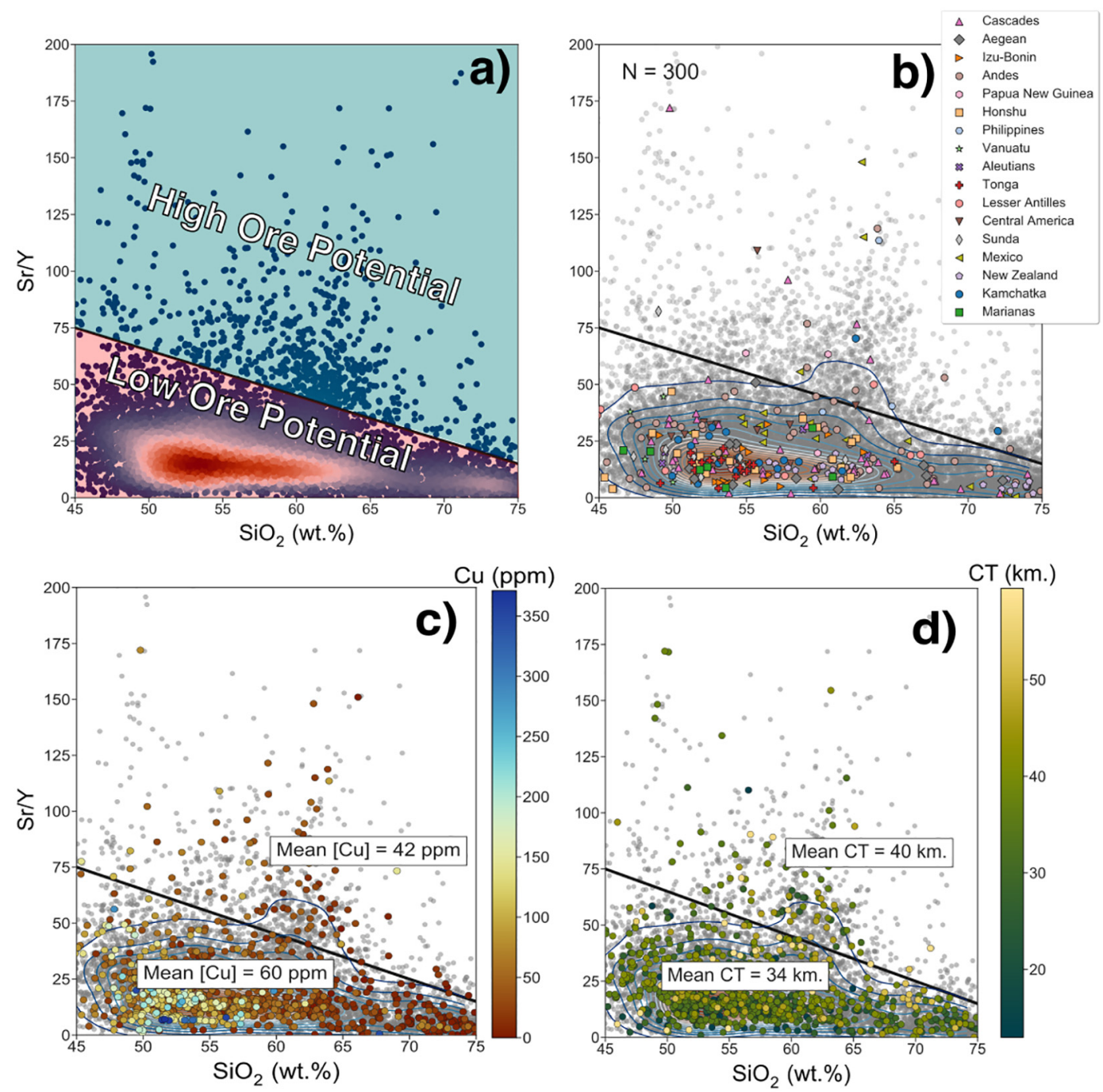

Fig. 2. $\mathrm{Sr} / \mathrm{Y}$ vs. $\mathrm{SiO}_{2}$ plots, colored for different features. Plots (b), (c), and (d) are both sub-sampled to only display 300 (b) and 1000 (c) and (d) samples for visual clarity. The black line in plot (a) differentiates "high" from "low" ore potential in arc magmas, as defined in the literature (Loucks (2014). Magmas sitting above the black line have a greater association with ore-forming deposits. Plot (a) is colored by the density of points in the total dataset, and contours for sample density are included in all subsequent plots. Plot (b) shows a sub-sample of arc magmas colored and symbolized by arc; notice how ore-producing arcs (e.g. the Andes) are the only ones that tend to proliferate above the high ore potential line. Plot (c) shows a sub-sample of the database colored for $\mathrm{Cu}$, where high and low ore potential magmas have mean [Cu] of 42 and 60 ppm respectively. Similarly, plot (d) shows that high ore potential magmas have thicker crust, on average, than low ore potential magmas.

The Sr/Y ratio, which compares the Large Ion Lithophile Element (LILE) $\mathrm{Sr}$ to the high field strength element (HFSE) $\mathrm{Y}$, is widely regarded as a proxy for high pressure fractionation of hydrous arc magmas (Richards, 2011; Chiaradia, 2014; Loucks, 2014). Strontium abundances during fractionation are primarily controlled by plagioclase (Ewart and Griffin, 1994), whereas Y abundances are controlled primarily by amphibole and garnet, as well as some minor phases like titanite (Green, 1994). The ratio of plagioclase to amphibole crystallized in a fractionating arc magma is decreased under conditions of high $\mathrm{H}_{2} \mathrm{O}$ activity (Grove et al., 2002; Stolper, 1982), which simultaneously stabilizes amphibole phases which incorporate $\mathrm{H}_{2} \mathrm{O}$ into their structure (Foden and Green, 1992). Thus, a hydrous magma should see abundant amphibole fractionation early in its differentiation in the mid to deep crust (up to $40 \mathrm{~km}$., (Ridolfi et al., 2010; Santana et al., 2020; Alonso-Perez et al., 2009) and late-stage plagioclase crystallization at or near volatile saturation in the upper crust (Loucks, 2014). This fractionation sequence will result in an elevated $\mathrm{Sr} / \mathrm{Y}$ ratio in deeply derived andesitic to dacitic magmas with significant amphibole (Loucks, 2014).

Fig. 3 shows $\mathrm{MgO}$ versus total $\mathrm{FeO}$ plots for global volcanic arc whole rocks, colour-coded for $\mathrm{Cu}$ contents (Fig. 3a and c), Sr/Y (Fig. 3 b) and crustal thickness (CT; Fig. 3d). These plots show that whole rocks with high $\mathrm{Cu}$ contents lie along a tholeiitic trend (with Fe-enrichment), whereas those whole rocks that lie along the calc-alkaline 

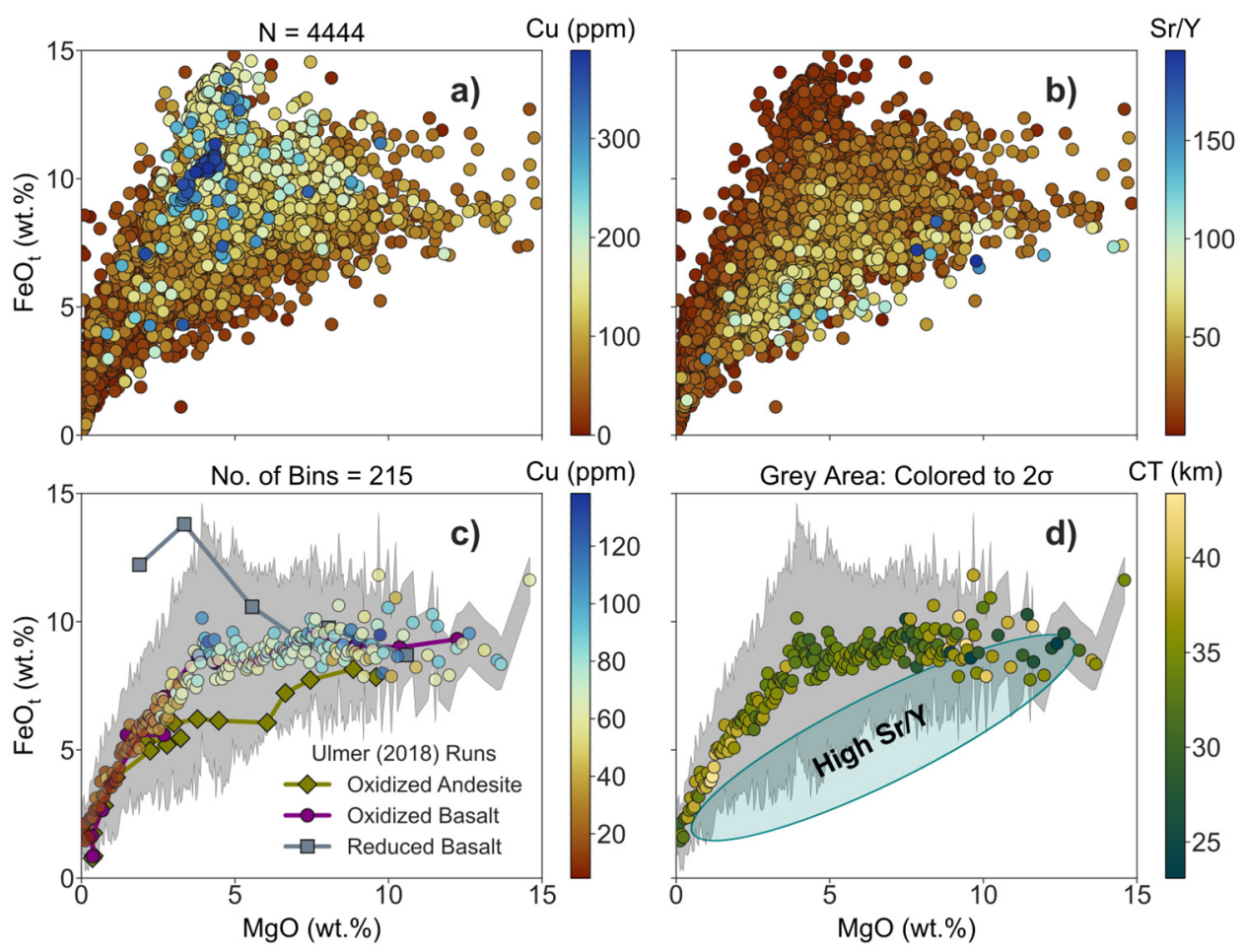

Fig. 3. Differentiation trends for the entire dataset, colored for $\mathrm{Cu}$ in (a) and (c), $\mathrm{Sr} / \mathrm{Y}$ in (b), and crustal thickness (CT) in (d). The highest Cu and $\mathrm{Sr} / \mathrm{Y}$ measurements are ordered to plot on top of lower measurements. In (c) and (d), resampled averages are calculated for the full database $(\mathrm{N}=<12,000)$ every $0.05 \mathrm{wt} . \%$ of $\mathrm{MgO}$. Standard deviations of the bins are colored out to $2 \sigma$, smoothed by a factor of 1.5 to reduce observed spread. Superimposed on the global database (c) are the $\mathrm{FeO}_{\mathrm{t}}$ and $\mathrm{MgO}$ wt.\% of empirical results of fractional crystallization experiments in arc conditions from Ulmer et al. (2018). The blue ellipse is the area where high $\mathrm{Sr} / \mathrm{Y}$ magmas plot in this Fig. 3d). (For interpretation of the references to colour in this figure legend, the reader is referred to the web version of this article.)

trajectory (with Fe depletion) are copper-poor. These calcalkaline rocks also have the highest $\mathrm{Sr} / \mathrm{Y}$ (Loucks, 2014). These observations are consistent with previous work (Richards, 2015; Chiaradia, 2014; Lee et al., 2012; Lee and Tang, 2020; Jenner, 2017).

We identify the principal processes responsible for the geochemical trends shown in Figs. 2 and 3 using rare earth element (REE) concentrations (Figs. 4 and 5). Fig. 4 shows data sorted so that the highest $[\mathrm{Cu}]$ and $\mathrm{Sr} / \mathrm{Y}$ points are placed "on top" of the data cloud to ensure the reader is not missing any of the highest $[\mathrm{Cu}]$ and $\mathrm{Sr} / \mathrm{Y}$ points. However, there are many more low $[\mathrm{Cu}]$ and $\mathrm{Sr} / \mathrm{Y}$ points, as shown in the Supplement via 3D scatter plots set up using the same axes and plot design (Fig. S10). The schematics in Figs. 4 and 5 show vectors for the fractionation of garnet, amphibole, olivine, plagioclase, orthopyroxene and clinopyroxene using an index of REE plot curvature, Dy/Dy* (Davidson et al., 2013). Essentially, Dy/Dy* estimates the relative depletion of the middle rare earth (MREE) Dy in relation to its light (LREE) and heavy (HREE) counterparts. The Dy/Dy* metric makes a weighted determination of the slope and shape of an REE spider diagram with respect to Dy, as:

$\frac{D y}{D y *}=\frac{D y_{N}}{L a_{N}^{4 / 13}+Y b_{N}^{9 / 13}}$

Dy/Dy* is of particular use for tracking amphibole/cpx and garnet fractionation (Davidson et al., 2013; Lee and Tang,
2020; Chen et al., 2019; Cox et al., 2019) in rock suites. Additionally, the trajectories for melting in the garnet source field are plotted following (Davidson et al., 2013). The ratio Dy/Dy* tends to be lowered by amphibole and clinopyroxene fractionation. These phases will deplete Dy relative to $\mathrm{Yb}$. Olivine, plagioclase, and orthopyroxene will drive Dy/Dy* towards higher values, as these phases do not incorporate Dy into their structure and thus Dy will be enhanced relative to light (LREE) and heavy (HREE) rare earth elements. Garnet fractionation will move $\mathrm{Dy} / \mathrm{Yb}$ to higher values during fractionation (i.e. deplete $\mathrm{Yb}$ relative to Dy) while simultaneously increasing Dy/Dy*. Mantle melting in the presence of garnet will lead to more moderate values of both $\mathrm{Dy} / \mathrm{Yb}$ and $\mathrm{Dy} / \mathrm{Dy}$ * if a garnet rich source is extensively melted.

The REE systematics of the global database can be further explored using a statistical approach (O'Neill, 2016), which compares parameters describing the shape of chrondrite-normalized multi-REE plots (Fig. 5). The REE polynomials, symbolized by $\lambda$, describe the shape of REE curves (O'Neill, 2016) based on multivariate statistics across all of the REEs (O'Neill, 2016). The polynomials are determined from the following calculation in orthogonal form:

$\ln \left([\mathrm{REE}] /[\mathrm{REE}]_{\mathrm{CI}}\right)=\lambda_{0}+\lambda_{1} \mathrm{f}_{1}^{\text {orth }}+\lambda_{2} \mathrm{f}_{2}^{\text {orth }}+\ldots$

Where the $f$ variables represents polynomials of REE atomic radius $\left(r_{R E E}\right)$, chosen to avoid co-correlation of the 

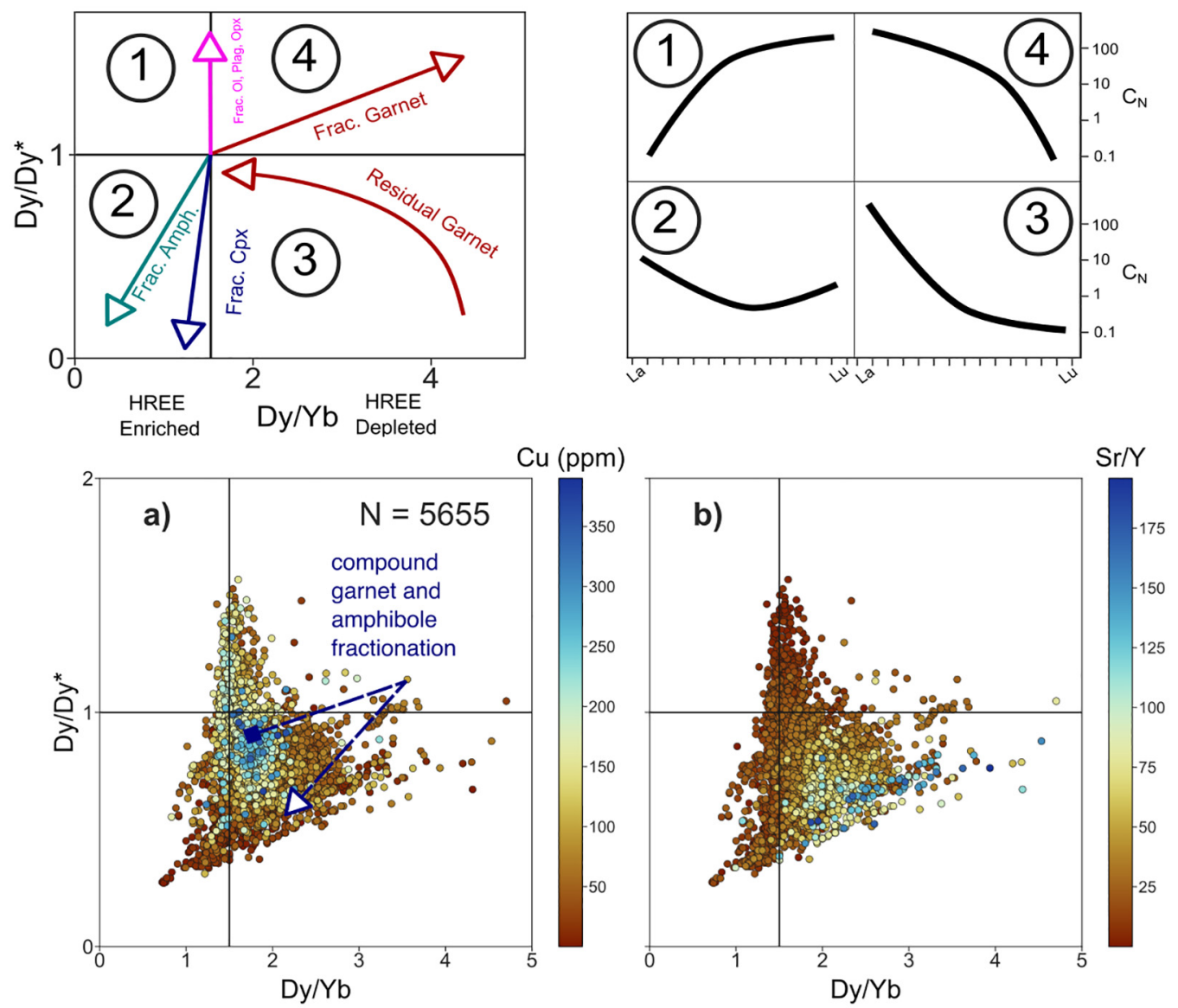

Fig. 4. Panels showing the distribution of (a) $\mathrm{Cu}$ and (b) $\mathrm{Sr} / \mathrm{Y}$ in Dy/Dy* vs. Dy/Yb space. These Dy plots show relative fractionation trends according to which mineral phase is dominant (Davidson et al., 2013). The starting point of each schematic mineral vector is in reference to a chrondrite normalized REE composition, following earlier modeling (Davidson et al., 2013). The lowest $\mathrm{Cu}$ and highest $\mathrm{Sr} / \mathrm{Y}$ magmas sit in an area generated by a combination of amphibole and garnet fractionation, and potential mantle source garnet melting. Points in (a) and (b) are ordered highest to lowest, with the highest $\mathrm{Cu}$ and $\mathrm{Sr} / \mathrm{Y}$ stacked on top. The dark blue arrow in plot (a) shows the expected differentiation path of a magma ascending from high to low pressure, and experiencing first garnet, then amphibole fractionation. Such a liquid line of descent (LLD) can explain the spread in the "high ore potential" field. (For interpretation of the references to colour in this figure legend, the reader is referred to the web version of this article.)

$\lambda$ s (O'Neill, 2016). A schematic at the right-hand side of Fig. 5 shows the effect of fractionation of amphibole/cpx and garnet on $\lambda$, expressed in terms of $\lambda 1$ and $\lambda 2$. Fig. 5 is subsampled to only color magmas for $\mathrm{Cu}$ (Fig. 5)a and $\mathrm{Sr} / \mathrm{Y}$ (Fig. 5b) where the whole rock composition shows $\mathrm{Sr} / \mathrm{Y}>50$ (considered the "high $\mathrm{Sr} / \mathrm{Y}$ " field in Fig. 3). In the section below we discuss these geochemical data, present an interpretative framework, and place it within the context of previous studies.

\section{DISCUSSION}

\subsection{Geochemical Characteristics of High Sr/Y Magmas}

We follow the example of Loucks (2014), in recognizing the close association between high $\mathrm{Sr} / \mathrm{Y}$ magmas and porphyry mineralization (Fig. 2a (Loucks, 2014)). Following this approach, this work shows that high $\mathrm{Sr} / \mathrm{Y}$ mag- mas show an association with continental arcs such as Mexico, the Andes and the Cascades (Fig. 2b and Supplementary Material), a low mean whole rock $\mathrm{Cu}$ concentration $(<50 \mathrm{ppm}$, Fig. 2c) and thicker crust (mean of $\sim 40 \mathrm{~km}$, Fig. 2d); these features are consistent with previous studies (Chiaradia, 2014; Chiaradia, 2015; Richards, 2015). These same magmas also sit in the high $\mathrm{Dy} / \mathrm{Yb}$, low Dy/Dy* quadrant of Fig. 4, and the high 22 , high $\lambda 1$ quadrant of Fig. 5. To confirm whether the mean $\mathrm{Cu}$ and crustal thickness differences in Fig. 2 between high and low $\mathrm{Sr} / \mathrm{Y}$ magmas is statistically robust, these values were compared using a two-way analysis of variance (ANOVA) hypothesis test, and a subsequent Tukey's highly significant difference (HSD) test. The null hypothesis tested in all cases was that the mean of a given measure is the same between two groups. The likelihood that this hypthesis is true due to random chance is calculated using an $\mathrm{F}$ statistic, given by: 

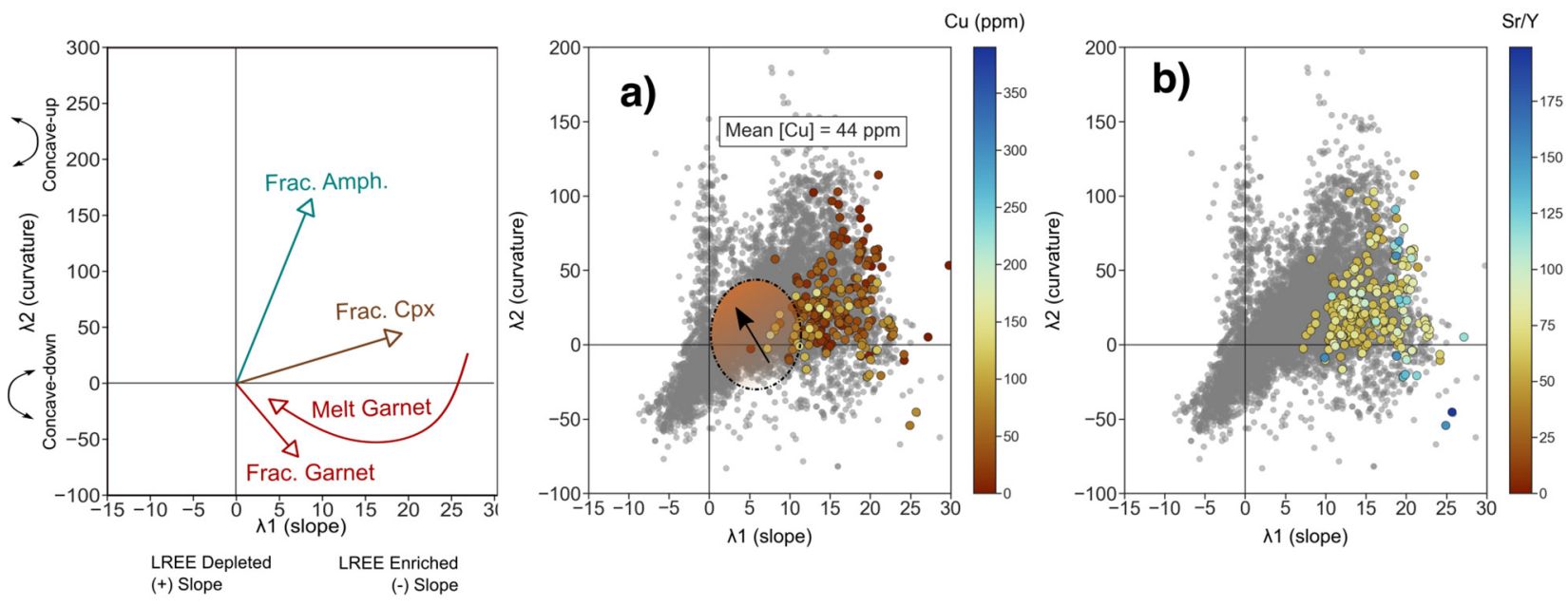

Fig. 5. REE behaviour as described by $\lambda$ spider-plot shape parameters O'Neill (2016). Top panels the right-hand panel is a schematic, showing how $\lambda 1$ vs. $\lambda 2$ plots describe mineralogical controls on REEs during differentiation, following O'Neill (2016). While $\lambda 1$ describes slope, it is calculated according to the radius of ordered REEs. Hence, a negative $\lambda 1$ corresponds to a positively sloped REE spider profile. (a) and (b) plot $\lambda 1$ vs. $\lambda 2$ colored for $\mathrm{Cu}$ and $\mathrm{Sr} / \mathrm{Y}$ respectively. Grey points show the entire global database. Colored points are those that plot in the high ore potential field of Fig. 3. Mean $[\mathrm{Cu}]$ of high Sr/Y field given in a). Empirical results from Ulmer et al. (2018) are shown in the orange shaded area in Figure (a), where the arrow denotes the evolving REE contents of empirical products in $\lambda$ space. (For interpretation of the references to colour in this figure legend, the reader is referred to the web version of this article.)
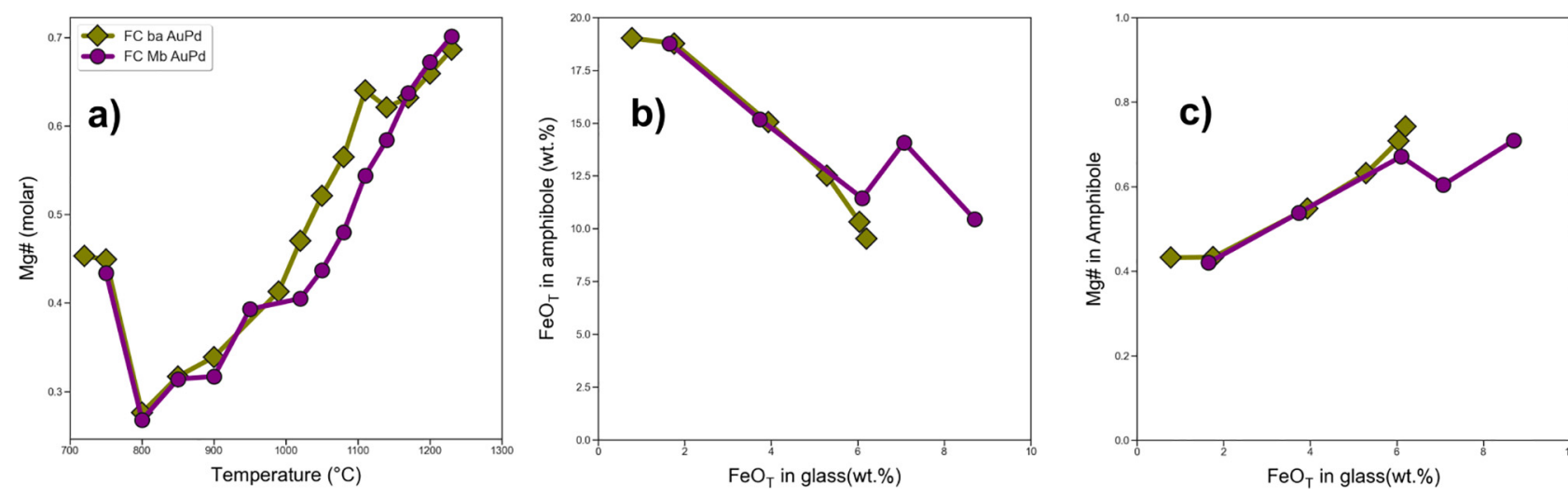

Fig. 6. Compilation of melt compositions as compared to the crystallization time and chemistry of amphibole in the empirical products analyzed in this study (Ulmer et al., 2018). Plot (a) shows the melt $\mathrm{Mg} \#$ as a function of temperature - amphibole stabilizes at $1050{ }^{\circ} \mathrm{C}$ for both FC ba AuPd and FC Mb AuPd. Plot (b) shows the FeO content of amphibole plotted against the FeO content of the corresponding silicate melt. Panel (c) shows the amphiboles $\mathrm{Mg \#}$ plotted against silicate melt FeO.

$F=\frac{\sum n_{j}\left(\bar{X}_{j}-\bar{X}\right)^{2} /(k-1)}{\sum \Sigma\left(X-\bar{X}_{j}\right)^{2} /(N-k)}$

Where $n_{j}=$ the sample size in the $j^{\text {th }}$ group, $\bar{X}_{j}$ is the sample mean in the $j^{\text {th }}$ group, $\bar{X}$ is the overall mean, $\mathrm{k}$ is the number of independent groups in the analysis, and $\mathrm{N}$ is the total number of observations in the analysis (Sullivan). This Fstatistic is compared to a critical-F at a given confidence threshold and degrees of freedom. We apply this ANOVA to both groupings of the ArcMetals database by crustal thickness and arc (see Supplement and GitHub). However, in this case, for a two-group comparison (e.g. comparing the high to low $\mathrm{Sr} / \mathrm{Y}$ group for one variable), a special case two-way ANOVA called a "student's t-test" was used. See the Supplement for information on the appliability of this $\mathrm{t}$-test, which uses the t-statistic rather than the $\mathrm{F}$ for hypothesis testing, but is applied much the same way as an ANOVA. After determining the p-value, which is a simple but easily misinterpreted measure of the likelihood of difference between the means occurring due to random chance, the difference between the different treatments (e.g. different arcs, different $\mathrm{Sr} / \mathrm{Y}$ groups) is compared using a Tukey HSD test (see method: https://www.statsmodels. org/stable/generated/statsmodels.stats.multicomp.pairwise tukeyhsd.html), which calculates the following test statistic:

$q_{s}=\frac{Y_{A}-Y_{B}}{S E}$ 

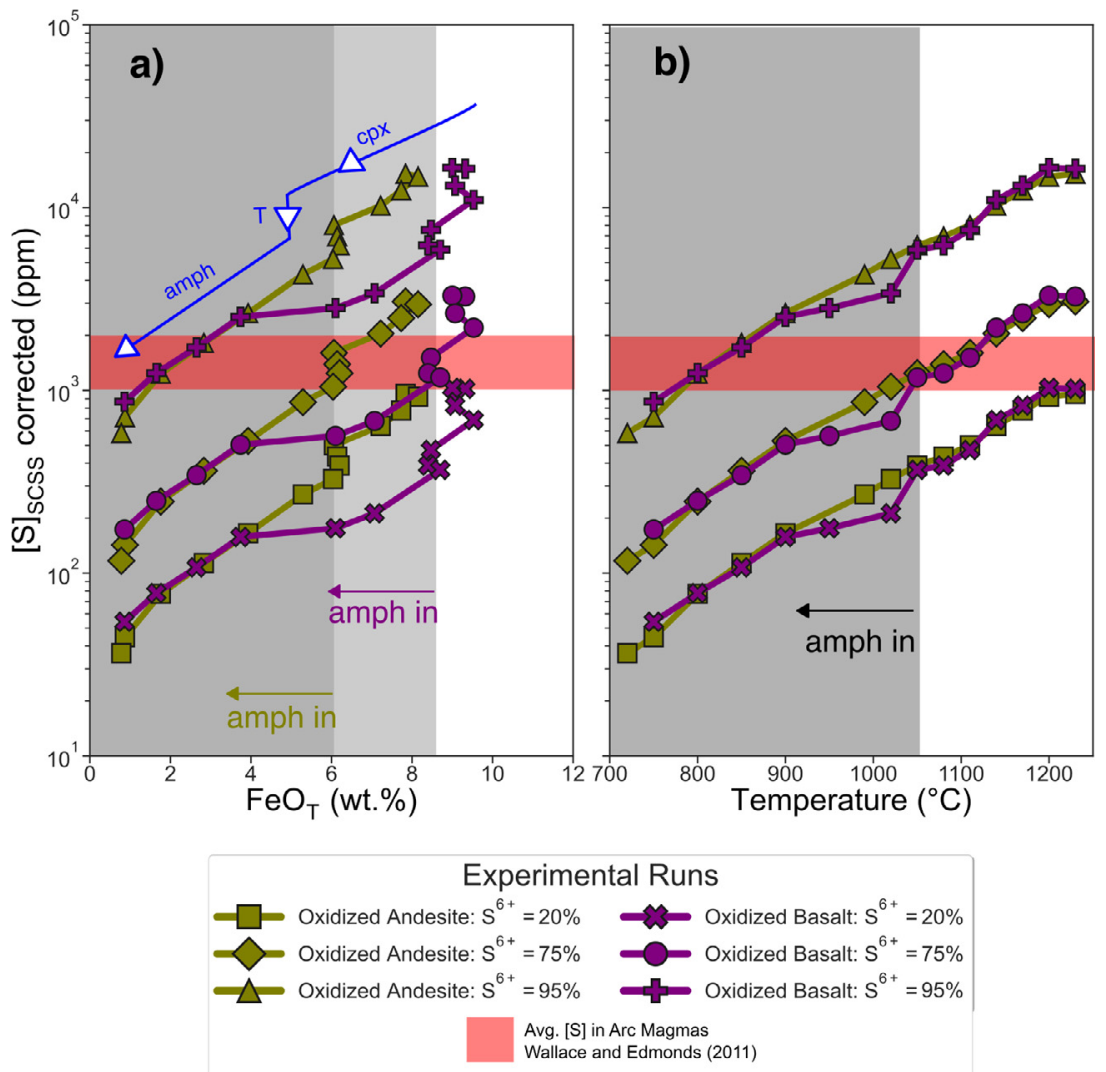

Fig. 7. Empirical results of glasses from Ulmer et al. (2018), using initial trace element abundances from Grove et al. (2002); Hurlimann (2016); Baker et al. (1994), and the SCSS model of O'Neill (2020). Plots show sulphur content at sulphide saturation (SCSS) on a log scale vs. (a) $\mathrm{FeO}_{\mathrm{t}}$ and (b) Temperature $\left({ }^{\circ} \mathrm{C}\right.$ ). Starting materials in each run were symbolized as: olive colored diamonds $=$ oxidized andesite; purple circles $=$ oxidized basalt (see text for details on these expeirmental runs). Vertical grey bars indicate the onset of amphibole fractionation for the oxidized andesite vs. the oxidized basalt runs, respectively. Amphibole is measured to appear around $6.5 \mathrm{wt} . \% \mathrm{FeO}$ and $1050{ }^{\circ} \mathrm{C}$. SCSS of the model andesite was reported for 3 proportions of $\mathrm{S}^{6+} / \Sigma \mathrm{S}-20 \%, 75 \%$, and $90 \%$ respectively, following the SCSS oxidation corrections found in Wieser et al. (2020). The red box covering the area between 1000 and $2000 \mathrm{ppm}[\mathrm{S}]$ is the average minimum [S] content in arc magmas, taken from Wallace and Edmonds (2011). The thick blue line and associated blue labels show the inferred dominant control on SCSS at different steps in the model. Discussion of partition coefficients used to model SCSS, $\mathrm{Cu}$, and $\mathrm{Sr} / \mathrm{Y}$ can be found in the main text and Supplement. (For interpretation of the references to colour in this figure legend, the reader is referred to the web version of this article.)

where $Y_{A}$ is the larger of the two means, $Y_{B}$ the smaller, and SE the standard error of the sum of the means. See the Supplement for detailed plots comparing the test statistics, tables with statistical outputs and constraints, and the code used in these analyses. The mean (1) $\mathrm{Cu}$ and (2) crustal thickness of the high and low $\mathrm{Sr} / \mathrm{Y}$ groups in Figs. 2c and $\mathrm{d}$ have been compared, respectively, using t-tests (high or low $\mathrm{Sr} / \mathrm{Y}$ ) t-tests, and these differences have been shown to be statistically significant ( $\mathrm{p} \ll 0.005$ ). Additional examples of statistical analyses on ArcMetals are shown in the example code.

The low mean $\mathrm{Cu}$ concentrations ([Cu]) in whole rocks associated with higher $\mathrm{Sr} / \mathrm{Y}$ (Fig. 2c) highlights the socalled "Cu-paradox" (Lee and Tang, 2020), where $\mathrm{Cu}$ is present in low abundance in the magmas that appear to be most capable of forming ore deposits. Observations such as these have been used to support porphyry formation models where crystallization of sulphide removes $\mathrm{Cu}$ from the silicate melts, to be later remobilized by one of several petrological processes (Lee and Tang, 2020; Wilkinson,
2013; Jenner et al., 2010; Park et al., 2019). However, it is also possible that melt $[\mathrm{Cu}]$ depletion may have little bearing on whether a magma goes on to form an ore deposit (Richards, 2015; Du and Audetat, 2020). While this initial analysis confirms the findings of prior studies that magmatic $[\mathrm{Cu}]$ is significantly lower in high $\mathrm{Sr} / \mathrm{Y}$ magmas on a global scale (Richards, 2015; Lee and Tang, 2020; Chiaradia, 2014), the petrological processes driving this association have not yet been resolved. To address this, empirical datasets are combined with simple trace element partitioning and sulphide saturation models to better understand what petrological processes are associated with high $\mathrm{Sr} / \mathrm{Y}$ and low $\mathrm{Cu}$ in magmas.

\subsection{Amphibole vs. Garnet Signatures}

Globally, it can be seen that both low $\mathrm{Cu}$ (Fig. 3)a and high $\mathrm{Sr} / \mathrm{Y}$ (Fig. 3b) volcanic whole rocks follow a calcalkaline path, showing consistent $\mathrm{Fe}$ loss with decreasing $[\mathrm{MgO}]$ (paralleling the high $\mathrm{Sr} / \mathrm{Y}$ ellipse in Fig. 3d). Similar 

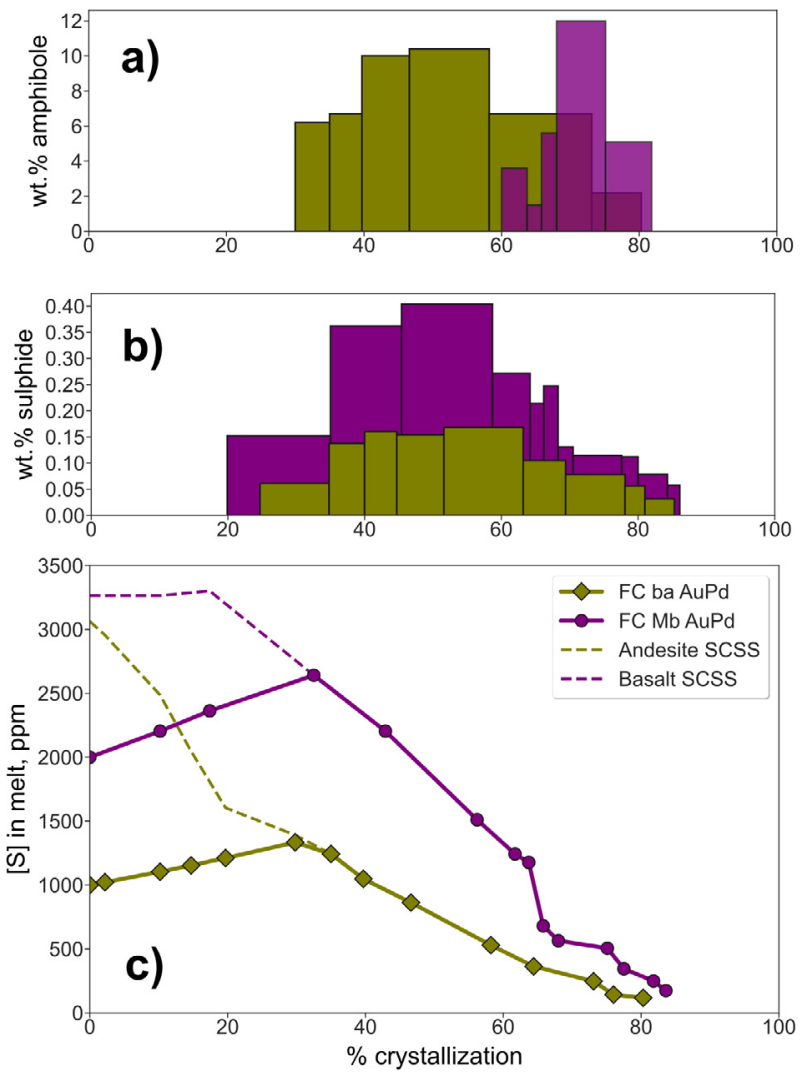

Fig. 8. Mass balance of sulphur and sulphide in empirical datasets of oxidized calc-alkaline andesite (FC ba AuPd) and basalt (FC Mb AuPd) (Ulmer et al., 2018). Panel (a) shows the mass fractionation of amphibole crystallizing at each step in the experiments of Ulmer et al. 2018. The mass balance model for sulphur and sulphide, discussed in the text (Section 4.3.4) provides estimates of (b) the mass of sulphide melt precipitating at each experimental step, and (c) the trend in $[\mathrm{S}]$ in these kinds of melts. Initial [S] values were fixed at $2000 \mathrm{ppm}$ for the basalt, and $1000 \mathrm{ppm}$ for the andesite (see text for details). The precipitating sulphide had its composition adapted from average sulphide melts at Merapi volcano, Indonesia (Nadeau et al., 2010).

results were obtained by earlier data compilations (Chiaradia, 2014; Chiaradia, 2015; Lee and Tang, 2020; Rezeau and Jagoutz, 2020). Fig. 3c and d plot the binned $\mathrm{FeO}$ and $\mathrm{MgO}$ concentrations that have been smoothed to show average $\mathrm{FeO}, \mathrm{MgO}, \mathrm{Cu}$ (Fig. 3)c, and crustal thickness (Fig. 3d) at 0.05 wt. $\% \mathrm{MgO}$ intervals. Fig. 3c also shows the fractional crystallization paths of experimentally synthesized and oxidized andesites and basalts (Ulmer et al., 2018), which also lie on the calc-alkaline trend displayed by high $\mathrm{Sr} / \mathrm{Y}$ magmas (more detail on these in Section 4.3).

Analysis of the global database suggests that high $\mathrm{Sr} / \mathrm{Y}$ arc magmas share key petrological features: they may undergo extensive fractionation of amphibole +/- clinopyroxene and garnet (they extend into the bottom left quadrant for Fig. 4, upper right in Fig. 5) and develop low $\mathrm{Cu}$ abundances during progressive differentiation (Fig. 4,a 5a). Whole rock compositions with the highest $\mathrm{Sr} / \mathrm{Y}$ ratios are characterized by concave-up REE profiles, where there is both HREE depletion and overall enrichment in the LREE (Fig. 4b). Fig. 4b shows a strong preference for high $\mathrm{Sr} / \mathrm{Y}$ magmas to sit in the bottom right "garnet-influenced" quadrant (high Dy/Yb, low Dy/Dy*), and Fig. 5a and b show many high $\mathrm{Sr} / \mathrm{Y}$ whole rocks sitting near the amphibole fractionation and garnet source field in $\lambda 1$ vs. $\lambda 2$ space (higher $\lambda 1$, higher 22 ). While there is a clear association between high $\mathrm{Sr} / \mathrm{Y}$, low $\mathrm{Cu}$ magmas and the amphibole fractionation field, the location of high $\mathrm{Sr} / \mathrm{Y}$ magmas at low Dy/Dy* and moderate Dy/Yb can also be explained through a magma formed in the "melting of mantle garnet" field (bottom right quadrant) which subsequently experienced (1) garnet fractionation at pressures around 1.2 GPa (Alonso-Perez et al., 2009), followed by (2) amphibole +/- clinopyroxene fractionation at lower pressures (AlonsoPerez et al., 2009). Whatever the exact sequence of processes, a magma plotting in the bottom-right quadrant of Fig. 4 must have experienced some HREE depletion and/ or LREE enrichment to match the predicted patterns of this metric (Davidson et al., 2013). Additionally, all magmas have a starting REE profile that may not begin at the "crosshair" intersection of the two bold black lines (defined for chrondritic-derived melt (Davidson et al., 2013)). Rather, each magma is likely derived from a mantle source with a unique REE profile defined by prior melt extraction, metasomatism, and other pre- and syn-melting features. Correcting for such source features is beyond the scope of this work, but would be an interesting area of ArcMetals to explore more fully. The complexities of the petrogenesis leading to changes in Dy/Dy* should make us cautious about using the Dy/Dy* systematics alone to diagnose the petrogenesis of high $\mathrm{Sr} / \mathrm{Y}$ magmas. Rather, any petrogenetic process proposed here must be validated by other independent metrics, empirical observations, and/or modeling.

This garnet to amphibole/cpx sequence may only be piecemeal at shallower pressures, where amphibole/cpx will dominate as a fractionating phase outside the stability field for garnet (Alonso-Perez et al., 2009). Thus, while the importance of amphibole in these systems will be demonstrated further, garnet likely also plays an important role, especially in the deep roots of arc magmatic systems (Alonso-Perez et al., 2009; Lee and Tang, 2020; Cox et al., 2020). By the same logic, the influence of clinopyroxene cannot be ruled out, as cpx will produce a similar compound fractionation trend as suggested by the blue line for amphibole-garnet in Fig. $4 \mathrm{a}$, albeit with a steeper slope. Clinopyroxene is one of the most common minerals in arc volcanic rocks, and empirical determinations of pyroxene stability indicate that amphibole-friendly magmatic conditions are comparably favourable for clinopyroxene (Ulmer et al., 2018; Alonso-Perez et al., 2009). However, amphibole is favoured over clinopyroxene at higher magmatic water contents (Alonso-Perez et al., 2009) and lower temperatures (Alonso-Perez et al., 2009; Ulmer et al., 2018) i.e. conditions more common in andesites stored in the shallow to mid-crust (aligning with the conditions of magmatic storage prior to porphyry formation (Chiaradia and Caricchi, 2017). Furthermore, the $\lambda$ plots show less ambiguously that high $\mathrm{Sr} / \mathrm{Y}$, low $\mathrm{Cu}$ magmas often have a much 
steeper slope, consistent with amphibole control as opposed to cpx (Fig. 5,a b). This emphasizes the importance of combining geochemical metrics to get the most out of whole rock data.

Garnet fractionation, as discussed in Section 1, has gained popularity in the recent literature as a potential ore fertility mechanism (Chen et al., 2019; Lee and Tang, 2020; Cox et al., 2020). Experiments have shown that garnet is stabilized as a fractionating phase at pressures above $0.8 \mathrm{GPa}$ (approximately $24 \mathrm{~km}$. depth)(Alonso-Perez et al., 2009; Greene et al., 2006) and where melt water contents are high (above 4 wt.\%) (Alonso-Perez et al., 2009). Direct evidence of garnet in arc magmas is rarely found in modern volcanics, but it has been found commonly in fossil arc systems (Bissig et al., 2017). Whether ancient or modern, where garnet can be seen widely in arc systems is in the lower crust cumulate lithologies of exhumed "arc roots," sections like the type section in Kohistan, Pakistan (Petterson, 2019; Jan and Howie, 1981; Ducea et al., 2015). Models developed for the mantle wedge underlying Central America found evidence for the presence of mantle heterogeneities rich in garnet-peridotite or garnet pyroxenite lithologies (Feigenson and Carr, 1993). Melting of such mantle garnet "veins" would impart a signature with higher $\mathrm{Dy} / \mathrm{Yb}$ than the arc array, as discussed in detail in previous work (Davidson et al., 2013; Feigenson and Carr, 1993).

While the role and importance of garnet fractionation is not disputed in explaining the occurrence of some magmas with low $[\mathrm{Cu}]$ in thicker-crust arcs (Cox et al., 2020; Lee and Tang, 2020), this analysis suggests that amphibole is also an important candidate for moderating global arc $\mathrm{Cu}$ systematics as shown in Figs. 4 and 5. The importance of amphibole has been previously proposed in the context of porphyry deposits (Loucks, 2014) and the broader controls on magmatic Fe (Richards, 2015), although in both of those cases REEs were not used as a metric to measure amphibole's presence. Amphibole fractionates in many arc magmatic environments at moderate $(15-40 \mathrm{~km}$.) depths (Ridolfi et al., 2010; Alonso-Perez et al., 2009), while also being verifiable petrographically in volcanic products, either as a primary phase or as an exhumed xenolith (Jeffery et al., 2013). Like garnet, amphibole is much more stable at high melt $\mathrm{H}_{2} \mathrm{O}$ contents (Greene et al., 2006; Ulmer et al., 2018; Alonso-Perez et al., 2009), but unlike garnet it predominates at moderate, not only deep crustal depths (20-55 km, Alonso-Perez et al., 2009; Santana et al., 2020; Ridolfi et al., 2010) rather than just deep depths. For many of the reasons the garnet hypothesis is favored, amphibole can be similarly supported as an important chemical control on the bulk chemistry of arc magmas. Amphibole will be stabilised at moderate to temperatures (between 800 and $1050{ }^{\circ} \mathrm{C}$ (Ulmer et al., 2018; AlonsoPerez et al., 2009)), moderate to high pressure (0.7-1 GPa (Alonso-Perez et al., 2009; Ridolfi et al., 2010)), and high water contents (Alonso-Perez et al., 2009). These results show, consistent with the literature, the strong and unambiguous importance of the association between amphibole in the fractionating assemblage and high $\mathrm{Sr} / \mathrm{Y}$ magmas (Richards, 2011; Richards, 2015; Loucks, 2014; Chiaradia, 2014). However, the mechanism by which amphibole obtains such an association, particularly with regards to $[\mathrm{Cu}]$, has not been explored in great detail in previous studies.

\subsection{Amphibole control on melt chemistry and sulphide stability}

To understand how amphibole is able to affect these global $\mathrm{Cu}$ trends, it is necessary to show how amphibole can provide a link between high $\mathrm{Sr} / \mathrm{Y}$, calc-alkaline, potentially porphyry-developing magmas, and their low $\mathrm{Cu}$ contents. This is first done by analyzing the empirical results of a well-constrained series of isobaric fractional crystallization experiments (Ulmer et al., 2018) in the context of the low $\mathrm{Cu}$, high $\mathrm{Sr} / \mathrm{Y}$ magmas centered in this work (Section 4.3.1). These empirical datasets are integrated with a trace element partitioning (reconstructing $\mathrm{Cu}, \mathrm{Ni}, \mathrm{Sr}, \mathrm{Y}$, and REE systematic) (4.3.1) and sulphide saturation (4.3.2) model to estimate the impact of amphibole on melt chemistry and subsequent sulphide systematics. Special attention is paid to amphibole's method of changing melt chemistry, with regards to the calc-alkaline differentiation trend discussed in Fig. 3. All of these empirical and modeled observations are synthesized together by a simple mass balance model to link the fractionation of amphibole with the stabilization of sulphide and subsequent depletion of $[\mathrm{Cu}]$.

\subsubsection{Analysis of empirical datasets}

Trace element abundances of experimental results from an existing empirical study (Ulmer et al., 2018) were modeled to constrain the effect of amphibole on the liquid line of descent in arc magmas, in order to understand how amphibole fractionation may connect major and trace element systematics under high $\mathrm{Sr} / \mathrm{Y}$-favoring conditions. The experimental study in question ran isobaric experiments under equilibrium (EC) and fractional crystallization (FC) conditions at $1.0 \mathrm{GPa}$ and from 1200 to $720^{\circ} \mathrm{C}$ on hydrous oxidized basaltic (Hurlimann et al., 2016) (called "FC Mb AuPd" in the original work) and oxidized andesitic (Baker et al., 1994) (called "FC ba AuPd" in the original work) composition melts.

The experimental data used in this work's model (Ulmer et al., 2018) were prepared by transcribing Table 1 (starting conditions), Table 2 (modal abundances of minerals at each experimental temperature step), and Table 3 (glass and amphibole compositions, determined by EPMA) into Supplemental Data Table 2 of this work. In Ulmer et al. 2018, major elements were the only measured chemical species. Starting abundances of $\mathrm{Ni}, \mathrm{Cu}, \mathrm{Sr}, \mathrm{Y}$, and all REEs were taken from the trace element compositions of the relevant starting materials (Baker et al., 1994; Hurlimann et al., 2016; Grove et al., 2002), and used to model the partitioning of trace elements into fractionating mineral phases following the methods of Shaw 2006 (Shaw et al., 2006):

$\frac{c_{l}^{t}}{c_{o}}=F^{D-1}$

where $\mathrm{t}=$ timestep $* \mathrm{t} *$ in a given experiment, corresponding to a specific set of T, $\mathrm{P}$, and $X_{i}$ conditions. Also called "run number" in Supplementary Table 2 our tab; $c_{l}^{t}=$ con- 
centration of an element in the residual liquid; $c_{o}=$ initial concentration of an element in bulk liquid, before fractionation; $F^{t}=$ fraction of residual liquid $\frac{L}{L_{o}} ; \mathrm{D}^{\mathrm{t}}=$ "Bulk D," or weighted sum of whole rock partition coefficients:

$D^{t}=\sum_{i=0}^{\infty} X_{i}^{t} * D_{i-l}^{t}$

where $X_{i}=$ mass fraction of mineral $i$ in accumulated solid fraction, and $D^{i-l}=$ partition coefficient (or $K_{d}$ ) between mineral $i$ and liquid $l$. Final form of Eq. (5) requires that $c_{l}$ is solved at each experimental step in the differentiation sequences:

$c_{l}=c_{o} * F^{D-1}$

The effect of these trace element models on elements like $\mathrm{Cu}$ and Ni can be found in the Supplement (Fig. S11). Note that of the three FC experiments total in the experimental database, only two are focused on in this work (i.e. the oxidized runs). The results from Ulmer et al. (2018) experienced some empirical complications around $900^{\circ} \mathrm{C}$, and the remaining melt fraction $(\mathrm{F})$ and resultant melt chemistry was reversed from what one would expect to occur naturally (decreasing $F$ with decreasing $T$ ). In order to make modeling these results as straightforward as possible, runs $10-12$ and 9-11 were discarded from the oxidized andesite and oxidized basalt experimental runs respectively. One of the most remarkable features of these empirical results is the well constrained liquid line of descent (LLD) for calc-alkaline, hydrous, moderately oxidized magmas, and the resulting association between LLD and major mineral phases like amphibole. Also remarkable is this empirical datasets constraint of the changes of $\mathrm{fO}_{2}$ with magmatic differentiation (Ulmer et al., 2018).

\subsubsection{Comments on amphibole's effect on $\mathrm{Mg \#}$}

Experimental work (Alonso-Perez et al., 2009; Ridolfi et al., 2010; Nandedkar et al., 2016; Ulmer et al., 2018) has already implicated amphibole as one of the most important phases controlling major element characteristics in high pressure calc-alkaline magmas. However, invoking amphibole as an important agent of melt chemistry change, as suggested f rom Figs. 4 and 5, raises the question of how amphibole, with an $\mathrm{Fe} / \mathrm{Mg}$ exchange coefficient ratio of around 0.3 (Nandedkar et al., 2016), can maintain the consistent melt $\mathrm{Mg} \#$ trend observed in calc-alkaline suites (see Fig. 3, high $\mathrm{Sr} / \mathrm{Y}$ trend). The calc-alkaline trend observed in high $\mathrm{Sr} / \mathrm{Y}$ magmas sees a constant decrease of $\mathrm{FeO}$ with $\mathrm{MgO}$, meaning that equal proportions of both elements have to be leaving the melt to explain the changes in melt chemistry. Despite the higher exchange coefficient of $\mathrm{Mg}$ in amphibole as compared to Fe (Ridolfi et al., 2010), some empirical work has noted that the majority of major element differentiation in metaluminous/peraluminous magmas should be controlled by amphibole at the relevant pressure and temperature conditions (Alonso-Perez et al., 2009).

To test this, the relationship between amphibole, melt

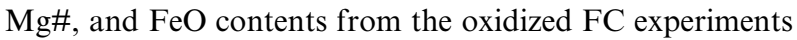
(Ulmer et al., 2018) has been plotted in Fig. 6. Where amphi- bole stabilizes at $1050^{\circ} \mathrm{C}$ (Fig. 6a), the $\mathrm{Mg \#}$ of the melt does not see the predicated rapid $\mathrm{Mg \#}$ drop off as a function of either temperature (Fig. 6a) or melt FeO wt.\% (Fig. 6b and c). Instead, melt $\mathrm{Mg \#}$ decreases smoothly through the amphibole stability field. Two major factors help to explain this trend: (1) coexisting phases crystallizing at the same time as amphibole, and (2) amphibole's increasing FeO content and correspondingly lower $\mathrm{Mg \#}$ as the magmas cools. Starting with the former, phases including clinopyroxene, garnet, plagioclase, ilmenite, and magnetite (in order of appearance) contribute to changes in melt chemistry in the andesite, and in the basalt, this series of other minerals also includes spinel. By mineral chemistry, phases like ilmenite, magnetite, spinel, garnet $(\mathrm{Fe} / \mathrm{Mg}$ exchange coefficient of around 0.7, Alonso-Perez et al., 2009), and even clinopyroxene contain enough iron to explain the consistent decrease in $\mathrm{FeO}$ seen in the empirical data modeled here. It should be noted however that amphibole is one of the dominant minerals in the fractionating sequence following its initial stabilization at $1050{ }^{\circ} \mathrm{C}$ - thus, a good portion of the changes in melt chemistry must be attributed to amphibole. Amphiboles stability may in fact be a marker all on its own of the right conditions contributing to calc-alkaline differentiation; contrast the trends seen in Fig. 3 for the oxidized andesite and oxidized basalt (Fig. 3c) with that of the reduced basalt (FC ba Pt-C), where the lack of amphibole contributes to the more tholeittic pattern of differentiation and a lack of $\mathrm{FeO}$ depletion.

Furthermore as the empirical (Ulmer et al., 2018) melts' reach temperatures below $900{ }^{\circ} \mathrm{C}$, Fig. $6 \mathrm{~b}$ and c show that amphibole itself begins to take on more iron into its structure. The stable amphibole species steps down from paragasite at temperatures $>900{ }^{\circ} \mathrm{C}$, to tschermakite $\left(900{ }^{\circ} \mathrm{C}\right)$, tschmerkatic hornblende $\left(800{ }^{\circ} \mathrm{C}\right)$, and finally magnesiohornblende $\left(720^{\circ} \mathrm{C}\right)$ at the end of each fractional crystallization experiment (amphibole names follow established nomenclature (Leake et al., 1997)). Not only does the $\mathrm{FeO}$ wt.\% of amphibole increase with greater degrees of differentiation, but Fig. $6 \mathrm{c}$ sees a decrease in the $\mathrm{Mg \#}$ of fractionating amphibole's as well. Fig. 6 shows that, consistent with the literature (Alonso-Perez et al., 2009; Ridolfi et al., 2010; Nandedkar et al., 2016; Ulmer et al., 2018), amphibole is not only associated with fractionating assemblages moving an arc magma towards calc-alkaline differentiation, but it can indeed alter the $\mathrm{FeO}$ content of a melt, in spite of its general preference for $\mathrm{Mg}$ cations over Fe. This extended discussion of amphibole's impact on $\mathrm{Fe}$ is pertinent to the crucial element of modeling done in this study, namely Fe's impact on sulphide saturation.

\subsubsection{Integrating sulphide models into empirical results}

To see whether major and trace element changes in a silicate melt affect the stability of sulphides in the melt requires an empirical model of sulphide saturation. Sulphide saturation is described by the experimental parameter, "sulphur content at sulphide saturation," or SCSS (O’Neill and Mavrogenes, 2002). Generally, SCSS is negatively correlated with pressure (O'Neill and Mavrogenes, 2002) and positively correlated with temperature (O'Neill and Mavrogenes, 2002; Nash et al., 2019; 
Smythe et al., 2017), melt $\mathrm{H}_{2} \mathrm{O}$ content (Fortin et al., 2015), melt $\mathrm{FeO}, \mathrm{Cu}$ and $\mathrm{Ni}$ contents (O'Neill and Mavrogenes, 2002; Kiseeva et al., 2017; Smythe et al., 2017; Kiseeva et al., 2017; Smythe et al., 2017; O’Neill, 2020), and oxygen fugacity $\left(\mathrm{fO}_{2}\right)$ (Jugo, 2009; Jugo et al., 2010; Nash et al., 2019). For mid-ocean ridge basalts, melt $\mathrm{FeO}$ content, oxygen fugacity $\left(\mathrm{fO}_{2}\right)$, temperature, and pressure are the main drivers of sulphide saturation (Kiseeva et al., 2017). In arc magmas, higher water and sulfur contents (Wallace and Edmonds, 2011; Edmonds and Mather, 2017) coupled with higher oxidation state (Richards, 2015; Jugo et al., 2010) cause the SCSS to respond differently as compared to MORB, though major elements like $\mathrm{FeO}$ still play a major role. For most arc magmas, volatile and oxidation conditions lie outside the range for which many SCSS models are calibrated (O'Neill and Mavrogenes, 2002), with some exceptions (Jugo et al., 2010; Fortin et al., 2015). Since most arc magmas have a considerable fraction of sulphur present as $\mathrm{S}^{6+}$, they may instead saturate in anhydrite, which is much more soluble in silicate melts (Zajacz and Tsay, 2019).

SCSS was modeled for the oxidized basalt and oxidized andesite runs (Figs. 3, 5, 6,7,8), using the major elements (Ulmer et al., 2018) and modeled trace elements $(\mathrm{Cu}, \mathrm{Ni})$ of the individual products as inputs using a new SCSS paramterization (O’Neill, 2020):

$$
\begin{aligned}
\ln \left[\mathrm{S}^{2-}\right]_{\mathrm{SCSS}}= & \Delta G_{\mathrm{FeO}-\mathrm{FeS}}^{O} / \mathrm{RT}+\ln C_{S^{2-}-} \ln a_{\mathrm{FeO}}^{\text {silmelt }} \\
& +\ln a_{\mathrm{FeS}}^{\text {Sulf }}
\end{aligned}
$$

This SCSS method builds on the work of (Smythe et al., 2017), and is very sensitive to the bulk silicate melt composition, the sulphide composition, $\mathrm{Fe}-\mathrm{Ni}-\mathrm{Cu}$ partitioning into that sulphide, and $\mathrm{P}$ and $\mathrm{T}$ at ranges appropriate for these models (O’Neill, 2020). For all experiments, SCSS decreases with $\mathrm{FeO}$ and decreasing temperature (Fig. 7a and b respectively) (O'Neill and Mavrogenes, 2002). The SCSS values are initially calculated assuming the redox state of the magma will favor mainly $\mathrm{S}^{2-}$ (O'Neill, 2020). To account for the likely abundance of $\mathrm{S}^{6+}$, SCSS was calculated for a range of potential $\mathrm{S}^{6+}$ speciation end members based on the $\triangle \mathrm{NNO}$ buffer values for $f \mathrm{O}_{2}$ measured in the modeled experiments. These values, 0.5, 1.0, and 1.5 $\triangle \mathrm{NNO}$, correspond to $\triangle \mathrm{QFM}$ values of $0.78,1.28$, and 1.78 respectively ( $\triangle \mathrm{NNO}$ to $\triangle \mathrm{QFM}$ conversion accomplished using the Excel tool "Calc-fO2-buffer' from http:// www.kaylaiacovino.com/tools-for-petrologists/, using data from previous work(Frost et al., 2001)). These $\mathrm{fO}_{2}$ values translate to $\frac{S^{6+}}{S_{T}}$ values of $0.2,0.75$, and 0.95 following a simple correction scheme developed for oxidized magmas (Wieser et al., 2020):

$\operatorname{SCSS}_{T o t}=\frac{S C S S^{2-}}{\left(1-\frac{S^{6+}}{\Sigma S}\right)}$

This in turn is based on an earlier parameterization of $\mathrm{S}^{6+}$ as a function of $\triangle Q F M$ buffer (Jugo et al., 2010):

$$
\frac{S^{6+}}{S_{T}}=\frac{1}{1+10^{(2.1-2 \Delta F M Q)}}
$$

Fig. 7 shows the results of modeling the different $\mathrm{S}^{6+}$ abundances in the magmas by using different symbols denoting the different oxidation state of $\mathrm{S}$ in each empirical dataset. The onset of amphibole crystallization is shown both as function of $\mathrm{FeO}$ (Fig. 7a) and temperature (Fig. 7b). To aid the reader in understanding what major minerals are fractionating during the experiments, a schematic blue line has been added to Fig. 7a showing the major controls on SCSS changes at different stages in the model. Where amphibole was the dominant fractionating phase in these experiments, there was only secondary involvement of minerals like garnet, magnetite, ilmentie, clinpyroxene, plagioclase, and spinel, though amphibole become less abundant as temperature continued to decrease (Ulmer et al., 2018). High-temperature $\left(>1050{ }^{\circ} \mathrm{C}\right) \mathrm{FeO}$ loss is attributed to clinopyroxene and to a lesser extent orthopyroxene and olivine (only in the basalt), followed by a much more amphibole (as well as garnet) mediated lowering of SCSS at temperatures below $1050{ }^{\circ} \mathrm{C}$. These two FeO loss trends, clinopyroxene vs. amphibole mediated, are separated by a small but abrupt decrease in SCSS, which is a function of temperature change as clinopyroxene abundance decreases and amphibole starts to appear (the "drop-off" on the blue curve in Fig. 7a).

The onset of amphibole fractionation is associated with a continued lowering of the SCSS, but no clear dramatic decrease (Fig. 7a, b). However, if we consider conditions relevant to porphyry development, clinopyroxene in these experiments only fractionates at temperatures greater than $1050^{\circ} \mathrm{C}$, which should be less common in the sort of mid-crust, high water, low $\mathrm{Cu}$ and high $\mathrm{Sr} / \mathrm{Y}$ magmas presumed to be important for developing porphyry systems. The continued drop in SCSS as a function of $\mathrm{FeO}$ (Fig. 7a) can be attributed to other phases stabilzing alongside amphibole, and the increasing $\mathrm{FeO}$ and decreasing $\mathrm{Mg \#}$ trends seen in amphiboles from Fig. $6 \mathrm{~b}$ and c. Since arc magmas usually contain bulk sulphur contents between 1000 and 2000 ppm (red box in Fig. 7a and b) (Wallace and Edmonds, 2011), these models confirm that most hydrous arc magmas are at or near sulphide saturation (Richards, 2015; Du and Audetat, 2020) during most of their differentiation, and as a result will become depleted in $\mathrm{Cu}$ as sulphides are removed; this hypothesis can be verified by further modeling (see Section 4.3.4). Furthermore, these magmas demonstrate that even with $\frac{S^{6+}}{S_{T}}$ values approaching 0.75 at $\triangle Q F M$ values greater than 1.2 (diamond and circle curves for andesite and basalt, respectively), sulphide fractionation can be pervasive.

The noticeable but not necessarily dramatic decrease in SCSS at amphibole-in is mediated by several competing factors: (1) As should be obvious from the SCSS paramaterization above, $\mathrm{FeO}$ is the crucial oxide driving much of the change in melt SCSS (O'Neill and Mavrogenes, 2002; O'Neill, 2020). Of particular importance is the activity of $\mathrm{FeO}$ in the melt, $a_{\mathrm{FeO}}$, which is affected by the activity coefficient of $\mathrm{FeO} \gamma_{\mathrm{FeO}}$ according to Eq. (8) (Eqn. 46 in original source(O'Neill, 2020)). (2) Different cations have a competing effect in this $\gamma$ term. For example, $\mathrm{MgO}$ has a strong negative correlation with $\gamma_{\mathrm{FeO}}$. This means that higher $\mathrm{MgO}$ will lower the activity coefficient of $\mathrm{FeO}$, mitigating 
the drop in SCSS as would be expected from $\mathrm{FeO}$ loss alone. Should olivine or another mafic phase precede amphibole fractionation as is the case for the oxidized basalt, the comparatively lower $\mathrm{MgO}$ will lead to a strong increase in $\gamma_{\mathrm{Fe}}$, magnifying the SCSS decrease. (3) By the same logic, the strong positive correlation between $\mathrm{Na}, \mathrm{K}$, and $\gamma_{\mathrm{FeO}}$, implies that a loss of alkali elements will enhance SCSS reduction during amphibole fractionation. So the SCSS-buffering effect is mitigated in part by a strong decrease in the alkali content of the model melt, promoting the continued SCSS decrease seen in Fig. 7. (4) The $\ln a_{F e S}^{S u l f}$ term, or the activity of the sulphide itself, has a large impact on SCSS. Related work has shown that the interplay between the $\mathrm{Fe}, \mathrm{Cu}$, and $\mathrm{Ni}$ abundances in sulphide is a strong control on the SCSS(Smythe et al., 2017). Hence, the models of $\mathrm{Cu}$ and $\mathrm{Ni}$ abundance in the trace element partitioning models included a small weight fraction (0.001) of sulphide fractionating at each step, assuming the sulphide in question is a sulphide melt (see next section for details), and using partition coefficients for $\mathrm{Cu}$ and $\mathrm{Ni}$ between sulphide melt and silicate melt from (Li et al., 2012). These Kd's are 1070 for $\mathrm{Cu}$, and 490 for $\mathrm{Ni}$, taken from experimental run LY04 ( $\mathrm{Li}$ et al., 2012). The consistent decrease of $\mathrm{Cu}$ and $\mathrm{Ni}$ in the silicate melt leads to a concurrent decrease in the sulphide $\mathrm{Fe} /(\mathrm{Fe}+\mathrm{Cu}+\mathrm{Ni})$ content in the hypothetical sulphide, and a corresponding decrease in the SCSS. Finally, (5) the continual decrease in temperature at constant pressure as performed in these experiments strongly affects the SCSS in the preferred SCSS model (O'Neill, 2020). This approach to modeling SCSS alongside calc-alkaline differentiated magmas shows the potential for amphibole to contribute to the modification of wholesale melt chemistry.

\subsubsection{Mass balance of amphibole's effect on $S$}

Fig. 7 shows the almost wholly linear decrease of modeled SCSS as the oxidized andesite and basalt runs progress. However, SCSS alone only tells half the story - to explain how amphibole fits into the story of the low $\mathrm{Cu}$, high $\mathrm{Sr} /$ $\mathrm{Y}$ magmas concerned in this work, there needs to be a compelling link between this decrease in SCSS and the melt's sulphur content $[\mathrm{S}]$. One way to demonstrate this is to take a similarly simple FC modeling approach as was done for the trace elements during the crystallization of the oxidized andesite and basalt. This is made possible if (1) there is a [S] imposed on each empirical melt, (2) the SCSS can be related to the $[\mathrm{S}]$ in such a way as to estimate the mass of sulphide fractionating at each step, and (3) the melt [S] can subsequently have been shown to have been perturbed by the modeled decrease in SCSS as a function of amphibole.

The results of these models are shown in Fig. 8. Fig. 8a shows the $\mathrm{w} \mathrm{t} \%$ of amphibole crystallizing in each experimental step (Ulmer et al., 2018). Amphibole stabilizes at $35 \%$ crystallization (or $\mathrm{F}=0.65$ ) in the oxidized andesite (FC ba AuPd), and $63.70 \%$ crystallization $(\mathrm{F}=0.363)$ for the oxidized basalt (FC Mb AuPd)(Ulmer et al., 2018). S contents in the melt were estimated based on inventories of $[\mathrm{S}]$ in the literature(Wallace and Edmonds, 2011), as the starting experimental materials did not have reported measurements of volatile trace elements like sulphur (Baker et al., 1994; Hurlimann et al., 2016; Ulmer et al., 2018). The modeling done here assumed an oxidized arc basalt to have a starting [S] of $2000 \mathrm{ppm}$, or 0.2 wt.\% (Wallace and Edmonds, 2011). Andesites should have already experienced some $[\mathrm{S}]$ loss, either as a consequence of degassing or as Fig. 3c shows as a result of basaltic differentiation and subsequent sulphide fractionation - thus, the oxidized andesite series was modeled as having a starting melt $[\mathrm{S}]$ of $1000 \mathrm{ppm}$ (corresponding roughly to the point the empirical basalt reached andesite-like melt compositions). Next, a simple mass balance was adapted from earlier work (Kiseeva and Wood, 2015) on sulphide's effect on [Cu] in MORB composition magmas:

$X_{\text {sulf }}=\frac{S_{o}-(S C S S)\left(X_{\text {melt }}\right)}{S_{\text {sulf }}}$

where $X_{\text {sulf }}=$ the mass fraction of sulphide produced at each experimental step; $S_{o}=$ the starting $[\mathrm{S}]$ in each step (initially 2000 and 1000 ppm respectively for the basalt and andesite); SCSS = the modeled SCSS value(O'Neill, 2020); $X_{\text {melt }}=$ the remaining fraction of melt, or F and; $S_{\text {sulf }}=$ the wt. $\%$ concentration of sulphur in the fractionating sulphide phase.

The goal of using this equation is to estimate the abundance of sulphide leaving the system once SCSS and [S] become equivalent, and by extension to model the decrease in $[\mathrm{S}]$ as a product of calc-alkaline differentiation. While the prior modeling in this work coupled with the original empirical results provide most of these parameters, this equation requires a fit to a particular sulphide composition, $S_{\text {sulf }}$. A suitable arc magma sulphide is required, one which was in equilibrium with basaltic to andesitic composition magmas, and which can also house significant amounts of $\mathrm{Cu}$ and $\mathrm{Ni}$. The sulphide chosen was an average sulphide melt modeled to be the parent of lower-temperature sulphides at Merapi volcano, Java, Indonesia (Nadeau et al., 2010). Sulphide melts were preferred here over other sulphide phases like pyrrhotite or cubanite because they are often primary to the original melt, and only decompose into other, crystalline sulphide phases at lower temperatures (Nadeau et al., 2010). The average sulphide melt from Merapi was estimated as having $38.2 \mathrm{wt} \%$ S, $52000 \mathrm{ppm} \mathrm{Cu}$, and $2300 \mathrm{ppm}$ Ni (Nadeau et al., 2010). Fitting this value as $S_{\text {sulf }}$ into Eqn. 11 allows us to construct a mass balance of sulphur in the empirical silicate melts analyzed in this study. The model results are presented as an Excel worksheet as Supplementary Table 5. As previously discussed, the silicate melts used here (Ulmer et al., 2018) correspond well to magmas stored at moderate depth under high $\mathrm{H}_{2} \mathrm{O}$, moderate to high pressure conditions. Thus, these results should be generalizable to many other hydrous arc andesites and basalts analyzed from ArcMetals and other compilations.

Fig. $8 \mathrm{~b}$ and c shows that amphibole crystallization corresponds to almost all of the sulphide fractionation and subsequent [S] loss in andesites. Starting from a basalt, amphibole stabilizes too late, such that amphibole plays only a marginal role in adjusting melt chemistry and corresponding sulphur and sulphide changes. Thus, conditions that favor olivine and pyroxene stability are conducive to 
widespread sulphide fractionation in the most primitive arc basalts, supporting our contention that most arc magmas experience pervasive sulphide saturation. However, this work has been much more concerned with the kind of andesitic, high $\mathrm{Sr} / \mathrm{Y}$ magmas that would predominate in the mid- to lower crust in porphyry-friendly settings. In andesites, amphibole is the only major phase crystallizing when sulphides stabilize (Fig. 8c). These coinciding trends are the combination of a lower $S_{o}$ (due to earlier basaltic sulphide fractionation) combined with the earlier stabilization of amphibole and subsequent amphibole-mediation of melt chemistry changes (e.g. Fig. 6). Thus it seems where an andesite begins to fractionate, amphibole is the dominant mediator of sulphide fractionation. This fits with general observations that those high $\mathrm{Sr} / \mathrm{Y}$, low $\mathrm{Cu}$ magmas (with measurable Dy/Dy* and $\lambda$ deviations consistent with amphibole) are likely intermediate composition trapped at depth. These results also suggest that it is amphibolemediated changes in andesite melt chemistry, in turn a function of melt temperature, that lowers SCSS enough to cause sulphide precipitation as the $[\mathrm{S}]$ in the melt increases slowly as a an incompatible element until reaching the SCSS (Fig. 8c). This again highlights the importance of amphibole as both a mediator of melt chemistry changes during calc-alkaline differentiation, and a signal of the optimal conditions for calc-alkaline and low $\mathrm{Cu}$ conditions in a melt. However, as Fig. 7 showed, amphibole isn't radically changing melt chemistry all on its own. Rather, the conditions associated with amphibole crystallization $\left(\mathrm{P}, \mathrm{T}, \mathrm{H}_{2} \mathrm{O}\right.$, $f \mathrm{O}_{2}$, melt chemistry) are conducive to a noticeable if modest decreases in SCSS, FeO (and other major elements), [S] and thus mass of sulphide fractionated and concurrent decrease in melt $[\mathrm{Cu}]$, where some but not all of these changes are directly the effect of amphibole. Equally important but not considered in depth in this work is the role of S degassing; should a magma degas significant volumes of sulphur, such that $[\mathrm{S}]$ in the melt falls well below the $1000+\mathrm{ppm}$ threshold set in Fig. 8, there is little chance sulphides will stabilize, and every chance that remaining sulphides will resorb and breakdown.

The presence of sulphides in magmas has been reported by an increasing number of studies, in areas as diverse as Western North America (Chen et al., 2019), Kilauea (Wieser et al., 2020), Réunion island (Collins et al., 2012), Tolbachik volcano, Kamchatka (Kamenetsky et al., 2017; Kamenetsky and Zelenski, 2020; Zelenski et al., 2018), Merapi (Nadeau et al., 2010; Nadeau et al., 2013) and Ijen (Berlo et al., 2014; Nadeau et al., 2016) volcanoes, Indonesia, the Ecuadorian (Georgatou et al., 2018) and ChileanAndean (Cox et al., 2019; Cox et al., 2020) volcanic zones, and sulphide-rich hornblende cumulate xenoliths (Chang and Audetat, 2018; Du and Audetat, 2020). The models and analyses presented here (Figs. 6-8), alongside the earlier compilations of whole rock major and trace element data (Figs. 2, 3, 4 and 5), provide compelling evidence that amphibole fractionation is a both a contributor to and signal of the cal-alkaline differentiation, extensive sulphide fractionation, and subsequent melt $[\mathrm{Cu}]$ depletion. This hypothesis is similar to a model proposed for another Ferich mineral, magnetite, which has been implicated in tak- ing up substantial quantities of $\mathrm{Fe}^{3+}$, and has been shown to lead to reduction of $\mathrm{S}$ from $\mathrm{S}^{6+}$ to $\mathrm{S}^{2-}$. Since sulphide saturates at much lower $[\mathrm{S}]$ as compared to sulphate (Jenner et al., 2010), higher proportions of $\mathrm{S}^{2-}$ will promote sulphide fractionation and metal loss. The crucial difference here is that amphibole's ability to promote sulphide fractionation and $\mathrm{Cu}$ loss is due to its reduction of total melt $\mathrm{FeO}$ and other oxides (like $\mathrm{Na}_{2} \mathrm{O}$ and $\mathrm{K}_{2} \mathrm{O}$ ), and amphibole's broader stability throughout the differentiation history of an andesite. Furthermore, if enough amphibole (and co-stable phases like ilmenite) reduce $\mathrm{FeO}$ enough, it is possible that magnetite fractionation could be more limited.

\subsection{Prevalence of Crystalline Sulphide Fractionation in Arc Volcanic Rocks}

Our analysis of the global database demonstrates that amphibole fractionation, accepted as one of the drivers of high whole rock $\mathrm{Sr} / \mathrm{Y}$ signals (Richards, 2011; Chiaradia, 2015; Loucks, 2014), can promote sulphide fractionation via $\mathrm{Fe}$-loss and consequent $\mathrm{Cu}$ depletion in a typical calcalkaline magma. The sulphide concerned is likely to at first be a sulphide melt (Nadeau et al., 2010), followed by a crystalline sulphide (e.g. monosulphide solid solution; MSS), which should predominate in the lower temperature conditions of an arc magmas as compared to MORB (Keith et al., 2017; Chang and Audetat, 2018; Rottier et al., 2019; Li and Audetat, 2013). While the modeling in this study has been concerned with the primary sulphide melt, a further consideration that needs to be explored is whether there is direct evidence linking MSS fractionation with $\mathrm{Cu}$ depletion in arc magmatic sequences. Such a connection would not only emphasize the pervasiveness of sulphide fractionation in arc magmas, but would also further implicate minerals like amphibole, clinopyroxene, and garnet as controls sulphide stability. This study attempts to provide such evidence by analyzing those whole rock compositions in ArcMetals that can be shown to have fractionated MSS sulphide. Fig. 9 plots whole rock $\mathrm{Cu} / \mathrm{Ag}$ vs. $\mathrm{MgO}$, coloured for both Gd/Yb (Fig. 9a), Dy/Dy* (Fig. 9)b, and for crustal thickness (CT) (Fig. 9c). The motivation behind constructing such plots stems from the fact that $\mathrm{Cu}$ fractionates more strongly into MSS than Ag (Patten et al., 2013; Li et al., 2012) (whereas the opposite is true in sulphide melts; sulphide melt fractionation should promote higher $\mathrm{Cu} / \mathrm{Ag}$ ), and such a ratio gives us the benefit of sensitively detecting the presence of a fractionating MSS at sulphide saturation (Jenner, 2017). A low $\mathrm{Cu} / \mathrm{Ag}$ ratio, below average midocean ridge basalt (MORB) (Jenner et al., 2012; Jenner, 2017) and continental crust (HHolland and Turekian, 2004), is consistent with crystalline sulphide fractionation and consequent $\mathrm{Cu}$ removal from the silicate melt (Jenner, 2017) at lower temperatures than were modeled in Fig. 7.

$\mathrm{Gd} / \mathrm{Yb}$ (Fig. 9a) is a proxy for garnet involvement in petrogenesis because Gd partitions less strongly into garnet than $\mathrm{Yb}$ (Jenner et al., 2012), and has been used to infer the prevalence of garnet fractionation in the Andes (Cox et al., 2020). The highest $\mathrm{Gd} / \mathrm{Yb}$ ratios are associated with whole 

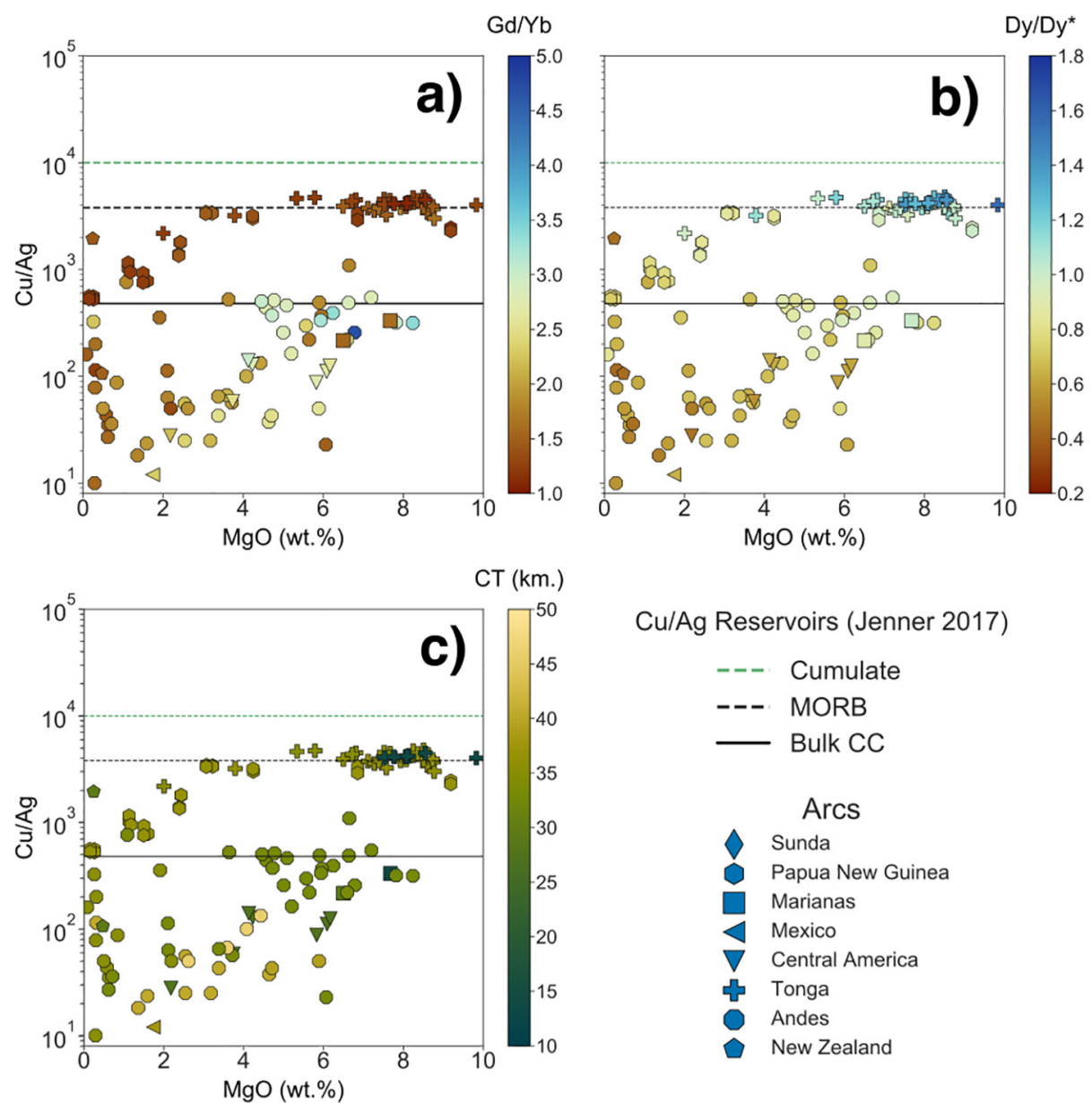

Cu/Ag Reservoirs (Jenner 2017)
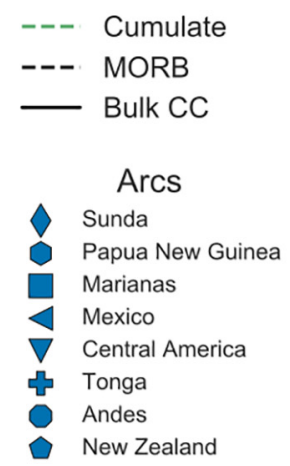

Fig. 9. $\mathrm{Cu} / \mathrm{Ag}$ (as a proxy for crystalline sulphide fractionation) plotted against $\mathrm{MgO}$. Colored for (a) $\mathrm{Gd} / \mathrm{Yb}$, (b) Dy/Dy*, and (c) crustal thickness $(\mathrm{CT}, \mathrm{km}$.). The majority of samples plotted here are whole rock compositions. Individual samples are symbolized according to the arc they come from. Plot structure and reference lines for $\mathrm{Cu} / \mathrm{Ag}$ adapted from Jenner (2017), as are the reference compositions for $\mathrm{Cu} / \mathrm{Ag}$ in sulphide cumulates, MORB, and Bulk CC. (For interpretation of the references to colour in this figure legend, the reader is referred to the web version of this article.)

rocks with the lowest $\mathrm{Cu} / \mathrm{Ag}$ for a given $\mathrm{MgO}$ content (Fig. 6a), suggesting a direct correlation between the proportion of garnet fractionation and the proportion of crystalline sulfide fractionation. Owing to the complexities in analysing whole rocks for $\mathrm{Ag}, \mathrm{Cu} / \mathrm{Ag}$ datasets are rare and are currently biased towards the Andes data, though there are some measurements in other transitional arcs (Fig. 9 symbols). There is no clear link between $\mathrm{Cu} / \mathrm{Ag}$ in the whole rock and crustal thickness plot, but the very thickest crust $(>40 \mathrm{~km})$ is associated with evolved volcanic rocks, with a higher $\mathrm{Gd} / \mathrm{Yb}$ (indicating garnet involvement) and low $\mathrm{Cu} / \mathrm{Ag}$. Fig. 6b shows that lower Dy/Dy*, indicative of amphibole, is also associated with low $\mathrm{Cu} / \mathrm{Ag}$, evolved magmas. Thus, both garnet and amphibole are implicated in the petrogenesis of magmas that have experienced the most crystalline sulphide fractionation. One drawback to using $\mathrm{Cu} / \mathrm{Ag}$ as a proxy for sulphides in the global database is the dearth of available $\mathrm{Ag}$ and other chalcophile data in the literature. Only in the past 5-10 years have $\mathrm{Ag}$ and other difficult to measure elements become easily measurable using ICPMS (Jenner, 2017;
Jenner and Arevalo, 2016; Cox et al., 2019; Cox et al., 2020; Wieser et al., 2020). As studies reporting suites of chalcophile elements in magmatic systems grow, future iterations of our ArcMetals database may yet be able to make broader, more detailed analysis of $\mathrm{Cu} / \mathrm{Ag}$ in arc systems. Furthermore, our earlier modeling (Figs. 7 and 8) suggest that a proxy like $\mathrm{Cu} / \mathrm{Ag}$ is not necessary to confirm sulphide fractionation, as sulphide fractionation should be a ubiquitous phenomenon in arc magmas, thanks to changes in SCSS mediated by phases like amphibole. However, natural data, without the benefit of the kind of thermodynamic knowledge available in empirical datasets, can still benefit form chalcophile trace element ratios like $\mathrm{Cu} / \mathrm{Ag}$.

It is worth noting that the $\mathrm{Gd} / \mathrm{Yb}$ content of a magma could be affected by both garnet fractionation, or meltderivation from a garnet rich source rock. If the latter, one would expect small fractional melts to have high $\mathrm{Gd} / \mathrm{Yb}$ followed by progressively lower $\mathrm{Gd} / \mathrm{Yb}$ as more and more Gd poor minerals melted out. To pick apart these competing REE trends (shown schematically in Dy/Dy* space in Fig. 4, and in $\lambda$ space in Fig. 5) is beyond the scope 
of this work. Prior work on $\mathrm{Cu} / \mathrm{Ag}$ establishes that particular volcanoes in the Andes likely experienced garnet fractionation as opposed to a mantle garnet signature (Cox et al., 2020). One way to assess how widespread mantlegarnet melting is as reflected in whole-rock geochemical records would be to compare a suite of garnetfractionating rocks to a suite of candidate garnet-melting rocks, like those analyzed for REEs in Central America (Feigenson and Carr, 1993). A few well constrained cogenetic suites of rocks, analyzed for REEs and plotted as a liquid line of descent in Dy/Dy* and $\lambda$ space would show what the relevant differences, if any, there are between garnet fractionation and garnet melting in complex natural magmas.

Our schematic model (Fig. 10) emphasizes the primary importance of amphibole fractionation and the related importance of garnet/clinopyroxene fractionation (Lee and Tang, 2020). This work emphasizes the importance of amphibole as a potentially widespread petrological-

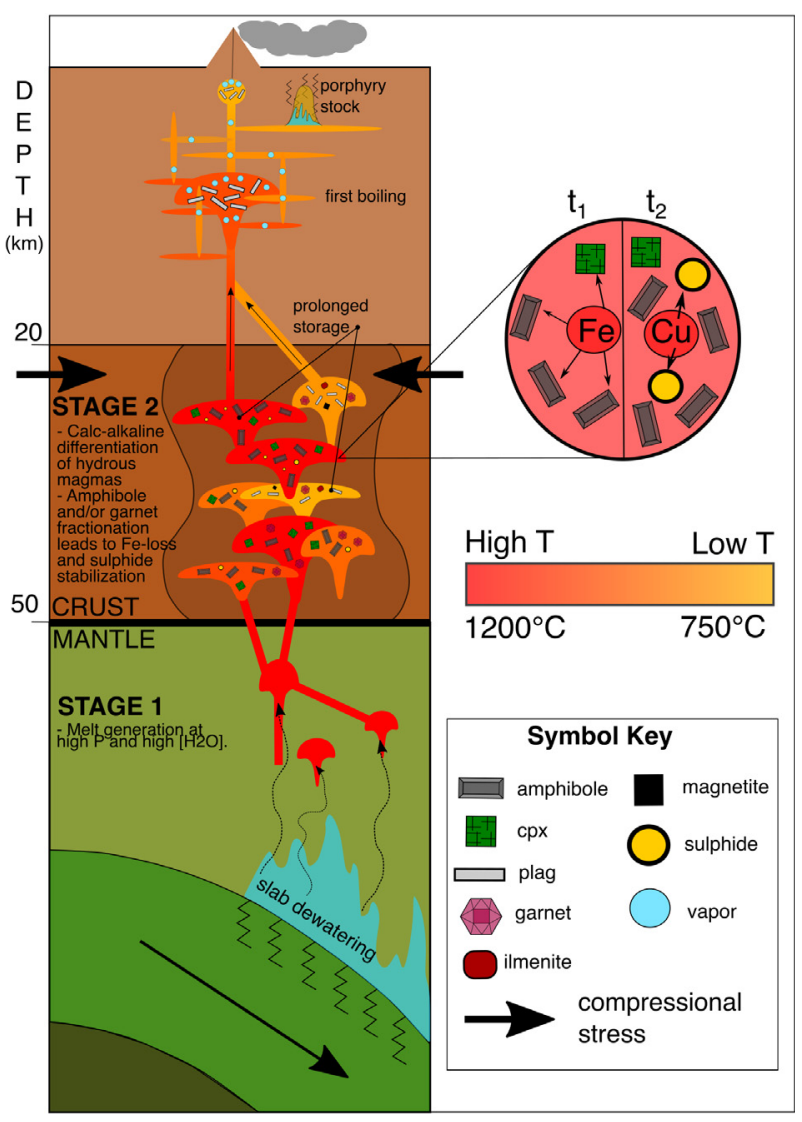

Fig. 10. Our proposed model for $\mathrm{Cu}$ depletion in arc magmas. This model takes into account the different geochemical and geophysical signals picked out by our database. Stage 1 sees hydrous melting under high pressure. High water contents of these calc-alkaline primitive melts contribute to prolonged amphibole fractionation in Stage 2, where magmas staled at depth $(=\mid<1 \mathrm{GPa})$ will fractionate enough amphibole to reduce $[\mathrm{Fe}]$ and stabilize sulphide. Garnet fractionation likely plays a role at depths $>50 \mathrm{~km}$, and could similarly deplete ore-fertile magmas in $\mathrm{Fe}$, leading to sulphide fractionation. control mechanism that explains many of the generic features of high $\mathrm{Sr} / \mathrm{Y}$ magmas in arcs. The global applicability of this amphibole-centred model complements garnet fractionation models, which work best in arcs with mature magmatic columns, deep brittle-ductile transitions (which promote longer residence times of magma in crust (Lee and Tang, 2020)), and thicker crusts (Lee and Tang, 2020; Cox et al., 2020). This amphibole model also complements the more immature arc focused magnetite fractionation models, which work best in young island arcs and/or back-arc basins (Jenner et al., 2010; Jenner et al., 2012). Our amphibole-centered model should be viewed on a continuum with these other petrological models, where waterrich, calc-alkaline trending arc magmas stored in the mid to deep crust (15-40 km.) will fractionate amphibole and stabilize sulphide in "semi-mature" arcs (called "immature continental arcs" as proposed in Lee et al. 2020, Fig. 6b (Lee and Tang, 2020)). The exact depth of storage, temperature, $f \mathrm{O}_{2}$, and amphibole stability in these magmas will depend on many geological, chemical, and physical factors, as elaborated on in relevant experimental results (Ulmer et al., 2018; Alonso-Perez et al., 2009; Nandedkar et al., 2016; Ridolfi et al., 2010). While the specific depth at which amphibole-mediated SCSS reduction will occur is variable, the important feature to note about this model is that amphibole represents a bridge between the magnetitedominated and garnet-dominated petrological models proposed in recent years. As these semi-mature arcs evolve, garnet will fill much the same role as amphibole in controlling $\mathrm{Fe}$ and stabilizing sulphide. This allows for a certain degree of temporal evolution in the primary petrological vector controlling bulk $[\mathrm{Cu}]$ in arc magmas, where one would expect a young, thermally immature arc to modulate its $\mathrm{Cu}$ via magnetite (Jenner et al., 2010), evolving to amphibole at a moderate maturity and thickness, culminating in garnet-dominated $\mathrm{Cu}$ control by the time the arc reaches maturity (Lee and Tang, 2020).

One point of departure with the analysis in this study as compared to previous studies relates the importance and timing of sulphide saturation. Some studies (Lee and Tang, 2020; Park et al., 2019) have assumed that early sulphide saturation is detrimental to eventual porphyry copper deposit development, articulating the ' $\mathrm{Cu}$ paradox,' of low magmatic $[\mathrm{Cu}]$ being associated with ore deposits (Lee and Tang, 2020). Studies using platinum group elements as proxies for sulphide saturation in arc systems make this assumption more explicit, arguing that ore development requires late sulphide saturation (Park et al., 2019). However, as suggested in recent work (Du and Audetat, 2020), porphyry systems that have experienced both prolonged amphibole fractionation and early sulphide crystallization (and subsequent $\mathrm{Cu}$ loss) seem perfectly capable of developing porphyry deposits later in their lifetime ( $\mathrm{Du}$ and Audetat, 2020). The global analysis shown here appears to confirm that melt $\mathrm{Cu}$ concentration does not act as a primary control on the potential of a magma to go on and make a porphyry deposit. Similarly, this amphibolemediated SCSS reduction model does not imply that amphibole fractionation is a critical missing link leading to porphyry development. Rather, widespread amphibole 
fractionation (as reflected by the petrography and/or whole-rock chemistry of a magma) is a consequence of particular magmatic conditions $\left(\mathrm{P}, \mathrm{T}, f \mathrm{O}_{2}\right)$ that might, under the right geological conditions, signal the right environment to develop a porphyry. Thus, amphibole is seen as a driver of melt chemistry and SCSS changes, but more an indicator of, rather than a driver of, porphyry development. In agreement with the observation that high $\mathrm{Sr} / \mathrm{Y}$ magmas have lower $\mathrm{Cu}$ concentrations (Richards, 2015; Lee and Tang, 2020) (Fig. 3c), this analysis finds that combined amphibole and/or garnet fractionation of whole rock chemistry (Fig. 4,5) can lead to early sulphide saturation (Figs. 7 and 8). The low magmatic $\mathrm{Cu}$ concentrations observed in the high $\mathrm{Sr} / \mathrm{Y}$ magmas in this database are fundamentally the consequence of the deep, hydrous evolution of arc magmas magmas. This crustal processing can lead to higher magmatic $\mathrm{H}_{2} \mathrm{O}$, promoting amphibole +/- garnet stabilization, and subsequently lower the SCSS enough to precipitate sulphides and reduce magmatic $[\mathrm{Cu}]$. While this implies that amphibole-dominated fractionation is thus a consequence of, rather than the cause of, magmas being able to form porphyry deposits, amphiboles abundance in deep-crust magmas is readily detectable by whole rock geochemistry, and could be used alongside other proxies to assess magmatic ore potential in porphyry settings.

\section{CONCLUSION}

In this study we present a comprehensive geochemical and geophysical database of volcanic whole rock samples across 17 arcs covering most of the Earth's active subduction zones. This database, ArcMetals, is differentiated from previous efforts by a rigorous filtration and data compilation strategy. Here, we present the first order features of this ArcMetals database alongside a simple trace element and sulphide saturation model to identify the key petrological processes that control $[\mathrm{Cu}]$ in arc magmas. More importantly, there is a strong association between high $\mathrm{Sr} / \mathrm{Y}$, calc-alkaline differentiation, and amphibole +/- garnet fractionation in conditions relevant to porphyry deposits. High $\mathrm{Sr} / \mathrm{Y}$ magmas show depletion of FeO during calcalkaline differentiation and are associated with significantly lower whole rock mean $\mathrm{Cu}$ concentrations and thicker continental crust. We show that trends are driven by extensive amphibole fractionation at temperatures below $1050^{\circ} \mathrm{C}$, which lowers melt $\mathrm{FeO}$ (and other major elements) and hence SCSS, driving widespread andesitic sulphide saturation and the removal of $\mathrm{Cu}$ into early forming sulphide melts. As has been shown in previous work, we contend that garnet fractionation can also contribute to Fe depletion, and subsequently increases the likelihood of sulphide saturation at greater depths before amphibole fractionates (Cox et al., 2020; Lee and Tang, 2020). However, this is not necessary on its own to stabilize sulphide. Rather, as our models of $\mathrm{S}$ in an empirical arc basalt show, even olivine and clinopyroxene can mediate a substantial drop in SCSS, leading to sulphide fractionation. On the whole, sulphide fractionation should be regarded as a widespread phenomenon early on in the history of arc magmas, where processes like magnetite, amphibole, and garnet fractiona- tion contribute to overall changes in melt SCSS and melt $[\mathrm{S}]$.

Amphibole, this study's preferred petrological vector, provides a generic explanation for global $\mathrm{Cu}$ systematics in semi-mature arc environments, as many calc-alkaline, oxidized arc magmas with (1) moderate to high water contents, (2) stored in the mid to deep crust at (3) moderate temperatures $\left(800-1050{ }^{\circ} \mathrm{C}\right)$ are easily able to stabilize and fractionate amphibole, evidenced by Dy/Dy* and $\lambda$ metrics and empirical data. Importantly, this analysis indicates that amphibole fractionation is, irrespective of the presence of garnet on the liquidus, capable of lowering SCSS and promoting early sulphide saturation, and is a useful indicator of the kind of geological conditions that might lead to later porphyry development. Furthermore, while magmatic $\mathrm{Cu}$ contents are found to be reflective of the crucial petrological processes identified in this and other studies, $[\mathrm{Cu}]$ is not found to be a primary driver or proxy for ore fertility on its own. Likewise, amphibole fractionation is a consequence of the kinds of conditions conducive to porphyry development, implying that amphibole could be used as a petrological and geochemical indicator for potential porphyry-developing magmas. While many arc magmas fractionate amphibole (Ridolfi et al., 2010) and most (if not all) arc magmas are rich in water and other volatiles, porphyry deposits remain rare. This study demonstrates early sulphide saturation is not necessarily detrimental to later porphyry formation from a typical calc-alkaline arc magmas, and that minerals like amphibole don't make porphyries, but rather are associated with porphyryfriendly physical and chemical conditions. Even more crucial to this process is the tectonic (e.g. compressional stresses), geodynamic, geological, and temporal conditions of the magma reservoir system itself (Du and Audetat, 2020; Chiaradia and Caricchi, 2017; Loucks, 2014; Richards, 2018), which along with the geochemical factors analyzed here, strongly influence whether or not a porphyry system will form. It is possible that porphyry mineralization requires long timescales for differentiation and fluid segregation (Chiaradia and Caricchi, 2017; Loucks, 2014) under conducive crustal configurations, which could promote further amphibole crystallization in a melt-rich mid-crustal hot zone (Chiaradia and Caricchi, 2017). Larger magma volumes may be optimal for achieving extreme volatile concentration(Rohrlach et al., 2005) (e.g. minimum $1000 \mathrm{~km}^{3}$ for Bingham Canyon and other large porphyry deposits (Chiaradia and Caricchi, 2017; Chelle-Michou et al., 2017)), which would also favor porphyry mineralization (Du and Audetat, 2020; Loucks, 2014; Chiaradia and Caricchi, 2017; Rezeau and Jagoutz, 2020).

\section{DATA AVAILABILITY}

All of our data, code, and protocols are available at the corresponding authors GitHub: https://github.com/ndb38/ arc-metals. The database and all associated code has been streamlined stream lined into a less crowded repository, and allowed to virtually run through Binder. This code will be updated in future versions of the database, but all the material pertaining to this paper will be preserved. 


\section{AUTHOR CONTRIBUTIONS}

NDB conceived the project with advice and comments from ME and FJ. NDB compiled the database, wrote the Python code, and performed the analysis. ME, FJ, AA, and $\mathrm{HW}$ provided equal contributions regarding data interpretations and significant references. NDB wrote the manuscript with equal editing contributions from ME, FJ, AA, and HW.

\section{Declaration of Competing Interest}

The authors declare that they have no known competing financial interests or personal relationships that could have appeared to influence the work reported in this paper.

\section{ACKNOWLEDGEMENTS}

We thank Callum Reekie for providing the Python code for the SCSS models, and for useful comments on SCSS. We thank Penny Wieser for providing a critical appraisal of our early database, and helpful comments regarding the SCSS and trace elements models and their outputs. An additional thank you is extended to James Crosby and Andrew Whyte for their early comments on the importance of amphibole. We would like to thank Associate Editor Adam Simon for his helpful and timely handly of the manuscript. We would also like to thank Cin-Ty Lee, Massimo Chiaradia, and two anonymous reviewers for their constructive comments. We would also like to thank the attendees of Goldschmidt 2020 for their constructive and supportive comments. We acknowledge funding from the NERC Centre for the Observation and Modelling of Earthquakes, Volcanoes and Tectonics (COMET). This work was supported, in whole or in part, by both the Bill \& Melinda Gates Foundation (Grant Number OPP1144) and the Gates Cambridge Trust. Under the grant conditions of the Foundation, a Creative Commons Attribution 4.0 Generic License has already been assigned to the Author Accepted Manuscript version that might arise from this submission.

\section{APPENDIX A. SUPPLEMENTARY MATERIAL}

Supplementary data associated with this article can be found, in the online version, at https://doi.org/10.1016/j. gca.2021.05.034.

\section{REFERENCES}

Arndt N. T. et al. (2017) Future global mineral resources. Geochem. Perspect. 6, 1-171.

Singer D. A., Berger V. I., Menzie W. D. and Berger B. R. (2005) Porphyry copper deposit density. Econ. Geol. 100, 491-514.

Richards J. P. (2015) The oxidation state, and sulfur and $\mathrm{Cu}$ contents of arc magmas: implications for metallogeny. Lithos 233, 27-45.

Chiaradia M. and Caricchi L. (2017) Stochastic modelling of deep magmatic controls on porphyry copper deposit endowment. Scientific reports $7,1-11$.

Blundy J., Mavrogenes J., Tattitch B., Sparks S. and Gilmer A. (2015) Generation of porphyry copper deposits by gas-brine reaction in volcanic arcs. Nat. Geosci. 8, 235-240.

Wilkinson J. J. (2013) Triggers for the formation of porphyry ore deposits in magmatic arcs. Nat. Geosci. 6, 917, https://www.- nature.com/articles/ngeol940\#supplementary-information (Oct 2013.

Lee C.-T. A. and Tang M. (2020) How to make porphyry copper deposits. Earth Planet. Sci. Lett. 529, 115868.

Richards J. (2003) Tectono-magmatic precursors for porphyry $\mathrm{Cu}$ (Mo-Au) deposit formation. Econ. Geol. 98, 1515-1533.

Richards J. P. (2011) Magmatic to hydrothermal metal fluxes in convergent and collided margins. Ore Geol. Rev. 40, 1-26.

Hedenquist, J.W. \& Lowenstern, J.B. The role of magmas in the formation of hydrothermal ore deposits. Nature 370, 519-527. ISSN: 0028-0836. http://www.nature.com/doifinder/10.1038/ 370519a0 (Aug. 1994).

Kiseeva E. S. and Wood B. J. (2013) A simple model for chalcophile element partitioning between sulphide and silicate liquids with geochemical applications. Earth and Planetary Science Letters., ISSN 0012821X.

Kiseeva E. S., Fonseca R. O. and Smythe D. J. (2017) Chalcophile elements and sulfides in the upper mantle. Elements 13, 111116.

Patten, C, Barnes, S.-J., Mathez, E.A. \& Jenner, F.E. Partition coefficients of chalcophile elements between sulfide and silicate melts and the early crystallization history of sulfide liquid: LAICP-MS analysis of MORB sulfide droplets. Chemical Geology 358, 170-188 (2013).

Jugo P., Candela P. and Piccoli P. (1999) Magmatic sulfides and $\mathrm{Au}: \mathrm{Cu}$ ratios in porphyry deposits: an experimental study of copper and gold partitioning at $850 \mathrm{C}, 100 \mathrm{MPa}$ in a haplogranitic melt-pyrrhotite-intermediate solid solution-gold metal assemblage, at gas saturation. Lithos 46, 573-589.

Simon A. C., Pettke T., Candela P. A., Piccoli P. M. and Heinrich C. A. (2006) Copper partitioning in a melt-vapor-brinemagnetite-pyrrhotite assemblage. Geochimica et Cosmochimica Ada 70, 5583-5600.

Li Y. and Audetat A. (2015) Effects of temperature, silicate melt composition, and oxygen fugacity on the partitioning of $\mathrm{V}, \mathrm{Mn}$ $\mathrm{Co}, \mathrm{Ni}, \mathrm{Cu}, \mathrm{Zn}, \mathrm{As}, \mathrm{Mo}, \mathrm{Ag}, \mathrm{Sn}, \mathrm{Sb}, \mathrm{W}, \mathrm{Au}, \mathrm{Pb}$, and $\mathrm{Bi}$ between sulfide phases and silicate melt. Geochimica et Cosmochimica Ada, ISSN: 00167037.

Li Y. and Audetat A. (2013) Gold solubility and partitioning between sulfide liquid, monosulfide solid solution and hydrous mantle melts: Implications for the formation of Au-rich magmas and crust-mantle differentiation. Geochimica et Cosmochimica Ada 118, 247-262.

Park J.-W. et al. (2019) Chalcophile element fertility and the formation of porphyry $\mathrm{Cu} \pm \mathrm{Au}$ deposits. Miner. Deposita 54, 657-670.

Jenner, F.E., ONeill, H.S. C, Arculus, R.J. \& Mavrogenes, J.A. The magnetite crisis in the evolution of arc-related magmas and the initial concentration of $\mathrm{Au}, \mathrm{Ag}$ and $\mathrm{Cu}$. Journal of Petrology. ISSN: 00223530 (2010).

Chiaradia M. (2014) Copper enrichment in arc magmas controlled by overriding plate thickness. Nat. Geosci. 7, 43-46.

Edmonds M. and Mather T. A. (2017) Volcanic sulfides and outgassing. Elements, ISSN: 18115217.

Nadeau O., Williams-Jones A. E. and Stix J. (2010) Sulphide magma as a source of metals in arc-related magmatic hydrothermal ore fluids. Nat. Geosci., ISSN: 17520894.

Audetat A., Pettke T., Heinrich C. A. and Bodnar R. J. (2008) Special paper: the composition of magmatic-hydrothermal fluids in barren and mineralized intrusions. Econ. Geol. 103, 877-908.

Du J. and Audetat A. (2020) Early sulfide saturation is not detrimental to porphyry $\mathrm{Cu}-\mathrm{Au}$ formation. Geology 48, 519524.

Loucks R. (2014) Distinctive composition of copper-ore-forming arcmagmas. Aust. J. Earth Sci. 61, 5-16. 
Rezeau H. and Jagoutz O. (2020) The importance of H2O in arc magmas for the formation of porphyry $\mathrm{Cu}$ deposits. Ore Geol. Rev. 103744.

Chelle-Michou C., Rottier B., Caricchi L. and Simpson G. (2017) Tempo of magma degassing and the genesis of porphyry copper deposits. Scientific reports 7, 40566.

Steinberger I., Hinks D., Driesner T. and Heinrich C. A. (2013) Source plutons driving porphyry copper ore formation: combining geomagnetic data, thermal constraints, and chemical mass balance to quantify the magma chamber beneath the Bingham Canyon deposit. Econ. Geol. 108, 605-624.

O'Neill, H. The thermodynamic controls on sulfide saturation in silicate melts with application to Ocean Floor Basalts. (2020).

Smythe D. J., Wood B. J. and Kiseeva E. S. (2017) The S content of silicate melts at sulfide saturation: new experiments and a model incorporating the effects of sulfide composition. Am. Mineral. 102, 795-803.

Jugo P. J., Wilke M. and Botcharnikov R. E. (2010) Sulfur K-edge XANES analysis of natural and synthetic basaltic glasses: Implications for $\mathrm{S}$ speciation and $\mathrm{S}$ content as function of oxygen fugacity. Geochimica et Cosmochimica Ada 74, 59265938.

Kiseeva E. S. and Wood B. J. (2015) The effects of composition and temperature on chalcophile and lithophile element partitioning into magmatic sulphides. Earth Planet. Sci. Lett. 424, 280-294.

Zajacz Z. and Tsay A. (2019) An accurate model to predict sulfur concentration at anhydrite saturation in silicate melts. Geochimica et Cosmochimica Ada 261, 288-304.

Nash, W.M., Smythe, D.J. \& Wood, B.J. Compositional and temperature effects on sulfur speciation and solubility in silicate melts. Earth and Planetary Science Letters 507, 187-198. ISSN: 0012-821X. http://www. sciencedirect.com/science/article/pii/ S0012821X18307155 (2019).

Chiaradia M. (2015) Crustal thickness control on $\mathrm{Sr} / \mathrm{Y}$ signatures of recent arc magmas: an Earth scale perspective. Scientific reports $\mathbf{5}, 8115$.

Farner M. J. and Lee C.-T. A. (2017) Effects of crustal thickness on magmatic differentiation in subduction zone volcanism: a global study. Earth Planet. Sci. Lett. 470, 96-107.

Ulmer P., Kaegi R. and Miintener O. (2018) Experimentally derived intermediate to silica-rich arc magmas by fractional and equilibrium crystallization at 1-0 GPa: An evaluation of phase relationships, compositions, liquid lines of descent and oxygen fugacity. J. Petrol. 59, 11-58.

Sarbas B. and Nohl U. (2008) The GEOROC database as part of a growing geoin-formatics network. Geoinformatics.

Hayes G. P. et al. (2018) Slab2, a comprehensive subduction zone geometry model. Science 362, 58-61.

Szwillus W., Afonso J. C., Ebbing J. and Mooney W. D. (2019) Global crustal thickness and velocity structure from geostatistical analysis of seismic data. Journal of Geophysical Research: Solid. Earth 124, 1626-1652.

Pasyanos M. E., Masters T. G., Laske G. and Ma Z. (2014) LITHO1. 0: An updated crust and lithospheric model of the Earth. Journal of Geophysical Research: Solid. Earth 119, 2153-2173.

Syracuse E. M. and Abers G. A. (2006) Global compilation of variations in slab depth beneath arc volcanoes and implications. Geochem. Geophys. Geosyst., ISSN: 15252027.

Richards, J.P. High $\mathrm{Sr} / \mathrm{Y}$ ratio magmas and porphyry $\mathrm{Cu}, \mathrm{Mo}, \mathrm{Au}$ De-posits: Just add water. Economic Geology 106, 1075-1081. ISSN: 0361-0128. (Nov. 2011).

Ewart A. and Griffin W. (1994) Application of proton-microprobe data to trace-element partitioning in volcanic rocks. Chem. Geol. 117, 251-284.
Green T. H. (1994) Experimental studies of trace-element partitioning applicable to igneous petrogenesis-Sedona 16 years later. Chem. Geol. 117, 1-36.

Grove T., Parman S., Bowring S., Price R. and Baker M. (2002) The role of an $\mathrm{H}_{2} \mathrm{O}$-rich fluid component in the generation of primitive basaltic andesites and andesites from the Mt. Shasta region, N California. Contrib. Miner. Petrol. 142, 375-396.

Stolper E. (1982) Water in silicate glasses: an infrared spectroscopic study. Contrib. Miner. Petrol. 81, 1-17.

Foden J. and Green D. (1992) Possible role of amphibole in the origin of andesite: some experimental and natural evidence. Contrib. Miner. Petrol. 109, 479-493.

Ridolfi F., Renzulli A. and Puerini M. (2010) Stability and chemical equilibrium of amphibole in calc-alkaline magmas: an overview, new thermobarometric formulations and application to subduction-related volcanoes. Contrib. Miner. Petrol. 160, 45-66.

Santana L. V., McLeod C., Blakemore D., Shaulis B. and Hill T. (2020) Bolivian hornblendite cumulates: Insights into the depths of Central Andean arc magmatic systems. Lithos 105618.

Alonso-Perez R., Miintener O. and Ulmer P. (2009) Igneous garnet and amphibole fractionation in the roots of island arcs: experimental constraints on an-desitic liquids. Contrib. Miner. Petrol. 157, 541.

Lee C.-T. A. et al. (2012) Copper systematics in arc magmas and implications for crust-mantle differentiation. Science 336, 64 68.

Jenner F. E. (2017) Cumulate causes for the low contents of sulfideloving elements in the continental crust. Nat. Geosci., ISSN: 17520908 .

Davidson J., Turner S. and Plank T. (2013) Dy/Dy*: variations arising from mantle sources and petrogenetic processes. $J$. Petrol. 54, 525-537.

Chen K. et al. (2019) Sulfide-bearing cumulates in deep continental arcs: The missing copper reservoir. Earth Planet. Sci. Lett. 115971.

Cox D., Watt S. F., Jenner F. E., Hastie A. R. and Hammond S. J. (2019) Chalcophile element processing beneath a continental arc stratovolcano. Earth Planet. Sci. Lett. 522, 1-11.

O'Neill H. S. C. (2016) The smoothness and shapes of chondritenormalized rare earth element patterns in basalts. J. Petrol. 57, $1463-1508$.

Sullivan, L. Hypothesis Testing - Analysis of Variance (ANOVA) https:// sphweb.bumc.bu.edu/otlt/MPH-Modules/BS/ BS704_HypothesisTesting-AN0VA/BS704_HypothesisTestingAnova_print.html.

Cox D. et al. (2020) Elevated magma fluxes deliver high-Cu magmas to the upper crust. Geology 48.

Greene A. R., DeBARI S. M., Kelemen P. B., Blusztajn J. and Clift P. D. (2006) A detailed geochemical study of island arc crust: the Talkeetna arc section, south-central Alaska. J. Petrol. 47, 1051-1093.

Bissig T., Leal-Meja H., Stevens R. B. and Hart C. J. (2017) High $\mathrm{Sr} / \mathrm{Y}$ magma petrogenesis and the link to porphyry mineralization as revealed by Garnet-Bearing I-type granodiorite porphyries of the Middle Cauca $\mathrm{Au}-\mathrm{Cu}$ Belt. Colombia. Economic Geology 112, 551-568.

Petterson M. (2019) The plutonic crust of Kohistan and volcanic crust of Kohistan-Ladakh, north Pakistan/India: lessons learned for deep and shallow arc processes. Geological Society, London, Special Publications 483, 123-164.

Jan M. Q. and Howie R. (1981) The mineralogy and geochemistry of the metamorphosed basic and ultrabasic rocks of the Jijal complex, Kohistan, NW Pakistan. J. Petrol. 22, 85-126. 
Ducea M. N., Saleeby J. B. and Bergantz G. (2015) The architecture, chemistry, and evolution of continental magmatic arcs. Annu. Rev. Earth Planet. Sci. 43, 299-331.

Feigenson M. D. and Carr M. J. (1993) The source of Central American lavas: inferences from geochemical inverse modeling. Contrib. Miner. Petrol. 113, 226-235.

Jeffery A. J. et al. (2013) The pre-eruptive magma plumbing system of the 2007-2008 dome-forming eruption of Kelut volcano, East Java, Indonesia. Contrib. Miner. Petrol. 166, 275-308.

Hurlimann N. et al. (2016) Primary magmas in continental arcs and their differentiated products: petrology of a post-plutonic dyke suite in the Tertiary Adamello batholith (Alps). J. Petrol. 57, 495-534.

Baker, M.B., Grove, T.L. \& Price, R. Primitive basalts and andesites from the Mt. Shasta region, N. California: products of varying melt fraction and water content. Contributions to Mineralogy and Petrology 118, 111-129 (1994).

Shaw D. M. et al. (2006) Trace elements in magmas: a theoretical treatment. Cambridge University Press.

Nandedkar R. H., Hurlimann N., Ulmer P. and Miintener O. (2016) Amphibole-melt trace element partitioning of fractionating calc-alkaline magmas in the lower crust: an experimental study. Contrib. Miner. Petrol. 171, 71.

Leake B. E. et al. (1997) Nomenclature of amphiboles; report of the subcommittee on amphiboles of the International Mineralogical Association, Commission on New Minerals and Mineral Names. The Canadian Mineralogist 35, 219-246.

O'Neill H. and Mavrogenes J. A. (2002) The sulfide capacity and the sulfur content at sulfide saturation of silicate melts at 1400 C and 1 bar. J. Petrol. 43, 1049-1087.

Fortin M.-A., Riddle J., Desjardins-Langlais Y. and Baker D. R. (2015) The effect of water on the sulfur concentration at sulfide saturation (SCSS) in natural melts. Geochimica et Cosmochimica Ada 160, 100-116.

Jugo P. J. (2009) Sulfur content at sulfide saturation in oxidized magmas. Geology 37, 415-418.

Wallace P. J. and Edmonds M. (2011) The sulfur budget in magmas: evidence from melt inclusions, submarine glasses, and volcanic gas emissions. Rev. Mineral. Geochem. 73, 215-246.

Frost B. R. et al. (2001) A geochemical classification for granitic rocks. Journal of petrology 42, 2033-2048.

Wieser, P., Jenner, F., Edmonds, M., Maclennan, J. \& Kunz, B. Chal-cophile elements track the fate of sulfur at Kilauea Volcano, Hawai'i (2020).

Li, Y. \& Audetat, A. Partitioning of V, Mn Co, Ni, Cu, Zn, As, $\mathrm{Mo}, \mathrm{Ag}, \mathrm{Sn}, \mathrm{Sb}, \mathrm{W}, \mathrm{Au}, \mathrm{Pb}$, and Bi between sulphide phases and hydrous basanite melt at upper mantle conditions. Earth and Planetary Science Letters (2012).

Collins S., Maclennan J., Pyle D., Barnes S.-J. and Upton B. (2012) Two phases of sulphide saturation in Reunion magmas: Evidence from cumulates. Earth Planet. Sci. Lett. 337, 104-113.

Kamenetsky V. S. et al. (2017) Silicate-sulfide liquid immiscibility in modern arc basalt (Tolbachik volcano, Kamchatka): Part II.
Composition, liquidus assemblage and fractionation of the silicate melt. Chem. Geol. 471, 92-110.

Kamenetsky V. S. and Zelenski M. (2020) Origin of noble-metal nuggets in sulfide-saturated arc magmas: A case study of olivine-hosted sulfide melt inclusions from the Tolbachik volcano (Kamchatka, Russia). Geology 48, 620-624.

Zelenski M., Kamenetsky V., Mavrogenes J., Gurenko A. and Danyu-shevsky L. (2018) Silicate-sulfide liquid immiscibility in modern arc basalt (Tol-bachik volcano, Kamchatka): Part I. Occurrence and compositions of sul-fide melts. Chem. Geol. 478, 102-111.

Nadeau O., Stix J. and Williams-Jones A. E. (2013) The behavior of $\mathrm{Cu}, \mathrm{Zn}$ and $\mathrm{Pb}$ during magmatic-hydrothermal activity at Merapi volcano, Indonesia. Chem. Geol. 342, 167-179.

Berlo K., van Hinsberg V., Vigouroux N., Gagnon J. and Williams-Jones A. (2014) Sulfide breakdown controls metal signature in volcanic gas at Kawah Ijen volcano, Indonesia. Chem. Geol. 371, 115-127.

Nadeau O., Stix J. and Williams-Jones A. E. (2016) Links between arc volcanoes and porphyry-epithermal ore deposits. Geology, ISSN: 19432682.

Georgatou A., Chiaradia M., Rezeau H. and Walle M. (2018) Magmatic sulphides in Quaternary Ecuadorian arc magmas. Lithos 296, 580-599.

Chang J. and Audetat A. (2018) Petrogenesis and metal content of hornblende-rich xenoliths from two Laramide-age magma systems in southwestern USA: insights into the metal budget of arc magmas. J. Petrol. 59, 1869-1898.

Keith M., Haase K. M., Klemd R., Schwarz-Schampera U. and Franke H. (2017) Systematic variations in magmatic sulphide chemistry from mid-ocean ridges, back-arc basins and island arcs. Chem. Geol., ISSN: 00092541.

Rottier B., Audetat A., Kodera P. and Lexa J. (2019) Origin and Evolution of Magmas in the Porphyry Au-mineralized Javorie Volcano (Central Slovakia): Evidence from Thermobarometry, Melt Inclusions and Sulfide Inclusions. J. Petrol. 60, 2449-2482.

Jenner F. E. et al. (2012) Chalcophile element systematics in volcanic glasses from the northwestern Lau Basin. Geochem. Geophys. Geosyst., ISSN: 15252027.

Holland, H.D. \& Turekian, K.K. Treatise on geochemistry (2004).

Jenner F. E. and Arevalo R. D. (2016) Major and trace elerment analysis of natural and experimental igneous systems using LAICP-MS. Elements, ISSN: 18115217.

Richards, J.P. A Shake-Up in the Porphyry World? Economic Geology 113, 1225-1233. ISSN: 0361-0128. (Sept. 2018).

Rohrlach B. D., Loucks R. R. and Porter T. (2005) Multi-millionyear cyclic ramp-up of volatiles in a lower crustal magma reservoir trapped below the Tampakan copper-gold deposit by Mio-Pliocene crustal compression in the southern Philippines. Super porphyry copper and gold deposits: A global perspective 2, 369-407. 